\title{
Article \\ Exploring the Ion Channel TRPV2 and Testicular Macrophages in Mouse Testis
}

\author{
Katja Eubler ${ }^{1}$, Pia Rantakari ${ }^{2}$, Heidi Gerke ${ }^{2}$, Carola Herrmann ${ }^{1}$, Annika Missel ${ }^{1}$, Nina Schmid ${ }^{1}$, Lena Walenta ${ }^{1}$, \\ Shibojyoti Lahiri ${ }^{3}$ (D) Axel Imhof ${ }^{3}$, Leena Strauss ${ }^{4,5}$, Matti Poutanen ${ }^{4,5}$ and Artur Mayerhofer ${ }^{1, *(D)}$
}

1 Cell Biology-Anatomy III, Biomedical Center Munich (BMC), Faculty of Medicine, Ludwig-Maximilian-University (LMU), D-82152 Planegg-Martinsried, Germany; katja.eubler@bmc.med.lmu.de (K.E.); carola.herrmann@bmc.med.lmu.de (C.H.); annika.missel@bmc.med.lmu.de (A.M.); nina.schmid@bmc.med.lmu.de (N.S.); lena.walenta@gmail.com (L.W.)

2 Turku Bioscience Center, University of Turku and Åbo Akademi University, FI-20300 Turku, Finland; piaranta@utu.fi (P.R.); hmsulo@utu.fi (H.G.)

3 Protein Analysis Unit, Biomedical Center Munich (BMC), Faculty of Medicine, Ludwig-Maximilian-University (LMU), D-82152 Planegg-Martinsried, Germany; Shibojyoti.Lahiri@med.uni-muenchen.de (S.L.); aimhof@med.uni-muenchen.de (A.I.)

4 Research Center for Integrative Physiology and Pharmacology, Institute of Biomedicine, University of Turku, FI-20300 Turku, Finland; leesal@utu.fi (L.S.); matpou@utu.fi (M.P.)

5 Turku Center for Disease Modeling, Institute of Biomedicine, University of Turku, FI-20300 Turku, Finland

* Correspondence: mayerhofer@bmc.med.lmu.de; Tel.: +49-89-218075859

check for updates

Citation: Eubler, K.; Rantakari, P.; Gerke, H.; Herrmann, C.; Missel, A.; Schmid, N.; Walenta, L.; Lahiri, S.; Imhof, A.; Strauss, L.; et al. Exploring the Ion Channel TRPV2 and Testicular Macrophages in Mouse Testis. Int. J. Mol. Sci. 2021, 22, 4727. https://doi.org/10.3390/ ijms22094727

Academic Editor: Karel Talavera

Received: 8 April 2021

Accepted: 26 April 2021

Published: 29 April 2021

Publisher's Note: MDPI stays neutral with regard to jurisdictional claims in published maps and institutional affiliations.

Copyright: (c) 2021 by the authors. Licensee MDPI, Basel, Switzerland. This article is an open access article distributed under the terms and conditions of the Creative Commons Attribution (CC BY) license (https:// creativecommons.org/licenses/by/ $4.0 /)$.
Abstract: The cation channel TRPV 2 is known to be expressed by murine macrophages and is crucially involved in their functionality. Macrophages are frequent cells of the mouse testis, an immuneprivileged and steroid-producing organ. TRPV2 expression by testicular macrophages and possible changes associated with age or inflammation have not been investigated yet. Therefore, we studied testes of young adult and old wild-type (WT) and $\mathrm{AROM}^{+}$mice, i.e., transgenic mice overexpressing aromatase. In these animals, inflammatory changes are described in the testis, involving active macrophages, which increase with age. This is associated with impaired spermatogenesis and therefore $\mathrm{AROM}^{+}$mice are a model for male infertility associated with sterile inflammation. In WT animals, testicular TRPV2 expression was mapped to interstitial CD206 ${ }^{+}$and peritubular $\mathrm{MHC} \mathrm{II}^{+}$ macrophages, with higher levels in $\mathrm{CD}^{206^{+}}$cells. Expression levels of TRPV2 and most macrophage markers did not increase significantly in old mice, with the exception of CD206. As the number of TRPV2 ${ }^{+}$testicular macrophages was relatively small, their possible involvement in testicular functions and in aging in WT mice remains to be further studied. In $\mathrm{AROM}^{+}$testis, TRPV2 was readily detected and levels increased significantly with age, together with macrophage markers and TNF- $\alpha$. TRPV2 co-localized with F4/80 in macrophages and further studies showed that TRPV2 is mainly expressed by unusual $\mathrm{CD} 206^{+} \mathrm{MHC} \mathrm{II}^{+}$macrophages, arising in the testis of these animals. Rescue experiments (aromatase inhibitor treatment and crossing with $\mathrm{ER} \alpha \mathrm{KO}$ mice) restored the testicular phenotype and also abolished the elevated expression of TRPV2, macrophage and inflammation markers. This suggests that TRPV2 ${ }^{+}$macrophages of the testis are part of an inflammatory cascade initiated by an altered sex hormone balance in $\mathrm{AROM}^{+}$mice. The changes in testis are distinct from the described alterations in other organs of $\mathrm{AROM}^{+}$, such as prostate and spleen. When we monitored TRPV2 levels in another immune-privileged organ, namely the brain, we found that levels of TRPV2 were not elevated in $\mathrm{AROM}^{+}$and remained stable during aging. In the adrenal, which similar to the testis produces steroids, we found slight, albeit not significant increases in TRPV2 in both $\mathrm{AROM}^{+}$and WT mice, which were associated with age. Thus, the changes in the testis are specific for this organ.

Keywords: TRPV2; testis; macrophages; aging; inflammation; $\mathrm{AROM}^{+}$; infertility 


\section{Introduction}

Transgenic mice overexpressing aromatase $\left(\mathrm{AROM}^{+}\right)$have been studied for many years [1-3]. The hormonal imbalance in these animals causes immunological changes and, in some organs, inflammation. A recent paper described higher plasma immunoglobulin levels, mainly IgE, in $\mathrm{AROM}^{+}$mice and distinct changes in the enlarged spleen [4]. The analysis of splenocytes revealed changes in the ratio of mature/immature B cells and increased IgE synthesis after IgE class-switching. Inflammatory changes in two organs were described, namely in the prostate and testis. In prostate, inflammation (prostatitis) and pre-malignant changes were found and occurred in an age-dependent manner [5]. In the inflammatory lesions several immune cell types, including mast cells, neutrophils, T-lymphocytes, and $\mathrm{F} 4 / 80^{+}$macrophages were present. In testis of $\mathrm{AROM}^{+}$, the most striking observations were the age-dependent increase in testicular macrophages positive for CD68, elevated TNF- $\alpha$ levels, and the parallel decline in spermatogenesis $[1,2,6,7]$. The changes became detectable at about 2 months of age and further increased with age. Of note, in many cases of human idiopathic male infertility due to impaired spermatogenesis, massive increases in testicular macrophage numbers, defined by the expression of CD68, occur, as well [8]. This and other similar changes led to the assumption that $\mathrm{AROM}^{+}$ mice are a model for human male infertility associated with sterile inflammation [9].

Tissue-resident macrophages of the testis have mainly been studied in rodents, and these studies indicated that macrophages normally participate in a broad spectrum of testis-specific functions, i.e., regulation of vascularization and morphogenesis [10], support of Leydig cell function [11], differentiation of spermatogonia [12], and maintenance of the immune privilege [13,14]. Macrophages are typically classified into inflammatory-activated (M1) and alternatively activated immunosuppressive macrophages (M2). M1 macrophages secrete proinflammatory mediators including large amounts of the proinflammatory cytokine TNF- $\alpha$. M2 macrophages are essential for tissue homeostasis, immune surveillance, and inflammation resolution and secrete low amounts of TNF- $\alpha$ [15]. For rodent testicular macrophages a polarization towards the immunoregulatory and immunotolerant M2 phenotype is typical. However, it is becoming clear that this state is not fixed and that the local environment governs the polarization of testicular macrophages [16]. Such regulatory influences play a role in inflammation and possibly also in aging of the testis. The last-mentioned point is not well known, but changes in testicular macrophage numbers during aging have been reported in rodents [17].

From a developmental point of view, the murine testis normally contains two different populations of macrophages, which have their origin predominantly in the fetal liver, as just very recently demonstrated [18]. Already at birth, a testicular compartment, i.e., the interstitial space is occupied by CD206 ${ }^{+} \mathrm{MHC} \mathrm{II}^{-}$macrophages, whereas CD206-MHC $\mathrm{II}^{+}$ ones surround the seminiferous tubules. Furthermore, a new study showed that after radiation or during infection, bone marrow-derived circulating monocytes are recruited to the testis and give rise to inflammatory macrophages which then promote tissue damage [19]. Hence, testicular macrophages can be heterogeneous.

The family of transient receptor potential (TRP) channels consists of a large group of rather ubiquitously expressed ion channels with a broad spectrum of functions and activating stimuli and is further divided into nine subfamilies (TRPA, TRPC, TRPM, TRPML, TRPN, TRPP, TRPS, TRPV, TRPVL), each comprising members with structural homology. All these channels have in common a relatively non-selective permeability for cations and all are regarded to act as molecular sensors. Among these channels, the transient receptor potential channel subfamily $\mathrm{V}$ member 2 (TRPV2) remains one of the least known channels [20]. It was considered as a thermal sensor for noxious heat $>50{ }^{\circ} \mathrm{C}$ [21] for a long time, however, TRPV2 has a much more complex physiology and properties, as demonstrated by knock-out mice [22]. Furthermore, the properties strongly depend on the species and cell type [23]. The known modulators include, in addition to noxious heat, $\triangle 9$-tetrahydrocannabinol (THC), cannabidiol (CBD), and 2-amino-ethoxydiphenyl borat (2-APB), acting as activators [24,25], and tranilast and ruthenium red, which represent 
antagonists [26,27], respectively. Yet all of these modulators lack specificity for TRPV2. Only very recently, it could be demonstrated that oxidation of a methionine residue within the structure of TRPV2 by reactive oxygen species (ROS), such as $\mathrm{H}_{2} \mathrm{O}_{2}$, or ultraviolet A light leads to activation and sensitization of TRPV2 [28], giving rise to endogenous regulatory mechanisms.

TRPV2 is reported to be expressed in different organs, including the brain [29], pancreas [30], muscle [31], spleen [21], and other immune-related tissues [32]. In the last decades, TRPV2 has been described to be crucially involved in innate and adaptive immunity and has been found in several cell types of the immune system in both human and mouse, i.e., in macrophages and osteoclasts, mast cells, granulocytes, monocytes, and also in T-lymphocytes [33-36]. In most of these cells, TRPV2 is essential for migration and it appears to be irreplaceable for differentiation of osteoclasts [37] or degranulation of mast cells $[33,36]$.

In macrophages, TRPV2 is essential for phagocytosis and chemotaxis [34,35,38]. TRPV2-deficient mice exhibit a higher bacterial load and increased mortality [22]. TRPV2 expression in macrophages was mainly demonstrated for resident populations, e.g., of brain, liver, skin, lung, and bone [39,40]. While a sizable number of organs and their respective macrophages were analyzed, the testis and in particular testicular macrophages have not been studied.

This paucity of information led us to perform this study. We examined, whether TRPV2 is expressed by mouse testicular macrophages, attempted to define the macrophage subtype by flow cytometry and studied, whether levels may change in old animals. Since TRPV2 is associated with inflammation we specifically focused on the testis of $\mathrm{AROM}^{+}$mice [1,2]. Additionally, the testicular tissue from known successful rescue experiments, i.e., treatment with an aromatase inhibitor [6] and crossbreeding with ER $\alpha \mathrm{KO}$ animals [41,42], were included in this study to gain insights into the regulation of TRPV2. Finally, we explored the expression of TRPV2 in the murine adrenal, i.e., an organ of steroid production, similar to the testis, and TRPV2 levels in the brain, which is similar to the testis, an immune-privileged organ.

\section{Results}

2.1. Testicular Expression of TRPV2, Macrophage and Inflammation Markers in Young and Old WT Mice

Whole testes lysates of young (2-3 months, $n=21)$ and old WT mice (6-8 months, $n=9$ ) were subjected to a detailed analysis employing quantitative RT-PCR and Western blotting. Next to TRPV2 and NOX2, we examined macrophage and inflammation markers. Testicular sections were further investigated by means of TRPV2 in situ hybridization and immunohistochemistry. In addition, we incubated the testicular tissue with cannabidiol (CBD), known to activate TRPV2, and screened for consequences of activation of TRPV2.

TRPV2 was detected at the mRNA level in young and old mice, and a slight, although not statistically significant increase of TRPV2 levels was found in old animals (Figure 1A). Immunoblotting did not reveal changes in TRPV2 level with increasing age (Figure 1B). Levels of the ROS generating enzyme NOX2 were slightly but not significantly higher in older animals (Figure 1A).

When testicular sections of both young (2 months, Figure S1A) and even older, 10 month-old, WT animals were examined by TRPV2 in situ hybridization (Figure 1C), we observed a distinct localization in the interstitial space (arrows) and within or in close proximity to the peritubular wall of seminiferous tubules (arrow heads).

Based on a detailed quantitative RT-PCR analysis, levels of all investigated macrophage markers, i.e., $C D 54, C D 68, C D 74$, and CD206, remained unchanged in old WT animals (Figure 1D), as well as the examined markers for inflammation, i.e., $C X C L-1, T I M P-1$, and TNF- $\alpha$ (Figure 1E). 
A

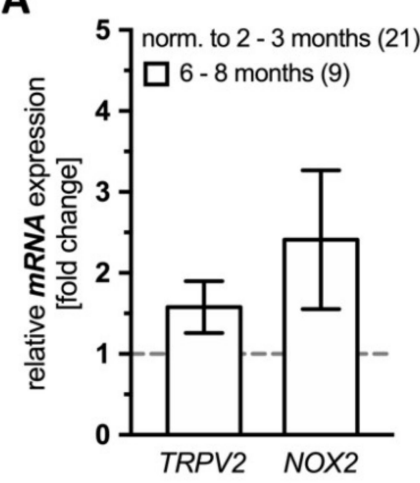

B
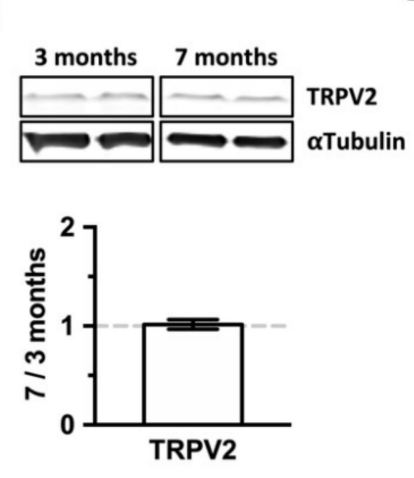

C

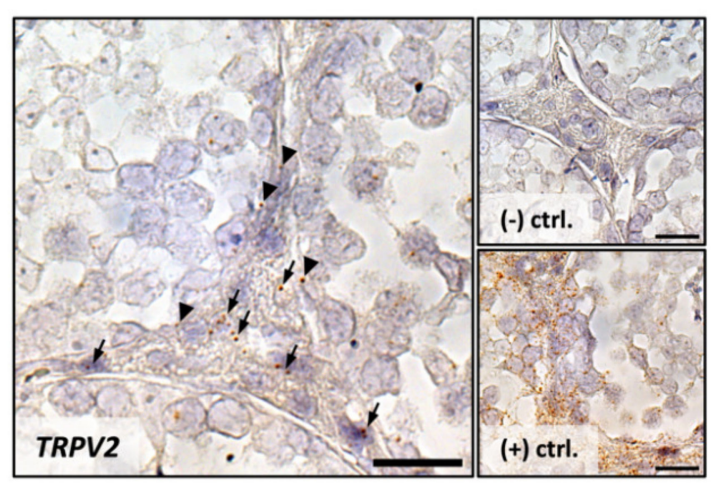

D

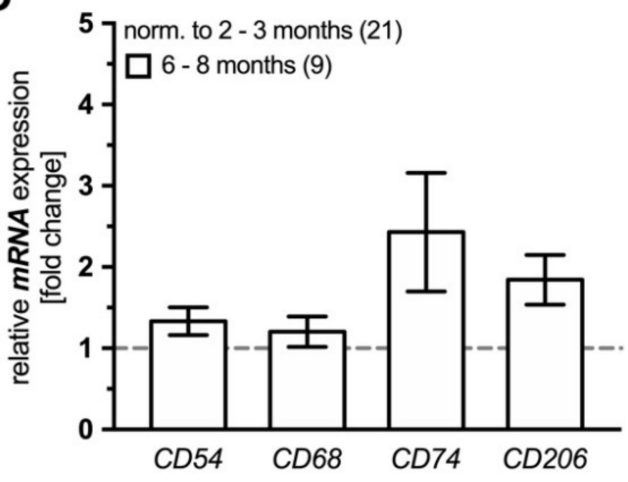

E

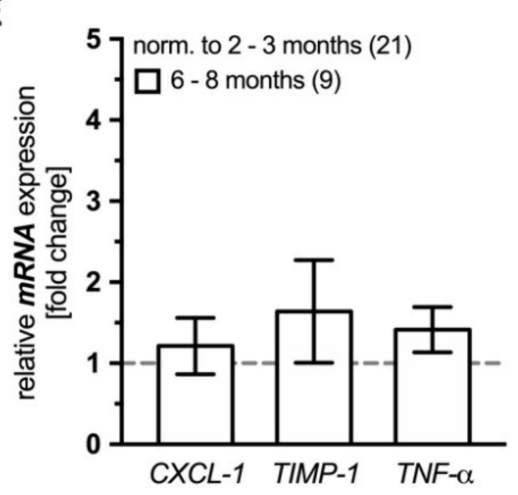

$\mathbf{F}$

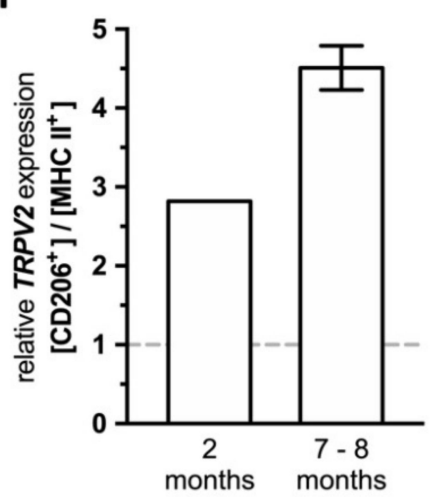

Figure 1. Expression profile of TRPV2, NOX2, macrophage and inflammation markers in WT testes. (A) Relative mRNA expression levels of TRPV2 and NOX2 in whole testes of old WT mice, normalized to young animals. Levels were not significantly different (TRPV2: $1.578 \pm 0.319, p=0.3505$; NOX2: $2.412 \pm 0.856, p=0.2802)$. (B) TRPV2 immunoblotting of young ( 3 months, $n=2)$ and old WT testes (7 months, $n=2)$ showed weak bands ( $63 \mathrm{kDa})$ for both ages and quantification revealed a mean expression level in old WT testis of $1.016 \pm 0.049$, compared to young ones. Staining for $\alpha$ Tubulin was used as a loading control. (C) Testicular sections of 10 month-old WT mice subjected to TRPV2 in situ hybridization showed punctuated staining mainly in the interstitial space (arrows) with few spots at the peritubular walls (arrow heads; left panel). The negative control (upper right panel, (-) ctrl.) showed no signals, but the positive control (lower right panel, $(+)$ ctrl.) did. Scale bar is $50 \mu \mathrm{M}$. (D,E) Relative mRNA expression levels of (D) macrophage markers (CD54: 1.332 \pm 0.172 , $p=0.1157 ; C D 68: 1.205 \pm 0.188, p=0.8506 ; C D 74: 2.430 \pm 0.732, p=0.2402 ; C D 206: 1.843 \pm 0.305, p=0.0589)$ and (E) inflammation markers (CXCL-1: $1.214 \pm 0.348, p=0.6767 ;$ TIMP-1: $1.638 \pm 0.633, p=0.7160 ;$ TNF- $\alpha: 1.416 \pm 0.279, p=0.5198$ ) in whole testes of old WT mice normalized to young animals. (A,D,E) The graphs represent mean \pm SEM of old WT mice (6-8 months, $n=9$ ) normalized to young animals (2-3 months, $n=21)$; unpaired two-tailed $t$-test, $\alpha=0.05$. (F) Testicular macrophages from young ( 2 months, $n=1$, pool of three animals) and old WT mice (7-8 months, $n=2$, pool of three animals each) sorted for their CD206 and MHC II expression by FACS were subjected to mRNA extraction and quantitative RT-PCR for TRPV2 expression. The graphs represent mean $\pm \mathrm{SEM}$.

To further characterize the macrophage subpopulation(s) expressing TRPV2, testicular macrophages were isolated and subjected to FACS for expression of CD206 and MHC II and then scanned for TRPV2 expression by quantitative RT-PCR (Figure 1F). In both young and old WT animals, CD206 ${ }^{+}$macrophages showed numerically higher TRPV2 expression levels compared to $\mathrm{MHC} \mathrm{II}{ }^{+}$ones (young: 2.820; old: $4.510 \pm 0.280$ ). This result suggests that predominantly interstitial macrophages express TRPV2, at least at the mRNA level (Figure 1C,F).

Since there was no change in TRPV2 expression in older animals, consequences of TRPV2 activation were explored in an organotypic incubation with testicular tissue from young WT mice (2-3 months, $n=6)$. The testicular tissue was pre-incubated with cannabinoid receptor 1 (CB1) and 2 (CB2) blockers, AM351 (80 nM) and AM630 (800 nM), respectively, for $1 \mathrm{~h}$ and then exposed to CBD $(30 \mu \mathrm{M})$ for $6 \mathrm{~h}$. 
Using a proteome profiler, a 2.596-fold higher CXCL-1 level could be detected in the supernatant of CBD treated tissue (4031.422 signal density/ $\mu$ g RNA) compared to the control tissue (1553.138 signal density/ $\mu$ g RNA) and an albeit weak signal for IFN-y was found exclusively in the CBD-treated tissue supernatant (128.919 signal density/ $\mu \mathrm{g}$ RNA; Figure S1B, upper panel).

A detailed quantitative RT-PCR analysis performed with mRNA isolated from the individual tissue pieces revealed significantly higher levels of CXCL-1 (1.767 \pm 0.326 , $p=0.0493), C X C L-2(1.807 \pm 0.334, p=0.0180)$, and $I L-6(1.697 \pm 0.174, p=0.0066)$ upon exposure to $30 \mu \mathrm{M}$ CBD, whereas CD54, COX2, IL-1 $\beta, M C P-1$, TIMP-1, TNF- $\alpha$, and TRPV2 remained unchanged (Figure S1B, lower panel).

\subsection{TRPV2, Macrophage and Inflammation Markers in Testes from Young and Old AROM ${ }^{+}$Mice}

In the testes of $\mathrm{AROM}^{+}$animals, TRPV2 was readily detected already in young adults, as shown by several methods. Testicular sections of both young (2 months, Figure S2) and old $\mathrm{AROM}^{+}$mice (10 months) were subjected to TRPV2 in situ hybridization. The results showed strong punctuated staining in the interstitial space, indicating that TRPV2 is present in large cells (Figure 2A). Immunohistochemistry using antibodies against the murine macrophage marker F4/80 (left panel) and TRPV2 (right panel) was also performed on consecutive sections from old $\mathrm{AROM}^{+}$animals (10 months). Immunoreactive signals indicate the co-localization of the two proteins and support the fact that testicular macrophages express TRPV2 in $\mathrm{AROM}^{+}$mice (Figure 2B).

Protein extracted from whole testis lysates of both young ( 3 months, $n=2)$ and old $\mathrm{AROM}^{+}$animals ( 7 months, $n=2$ ) further confirmed the increase in TRPV2 amount $(1.987 \pm 0.378$; Figure 2C).

Comparing young ( $2-3$ months, $n=21)$ and old $\mathrm{AROM}^{+}$mice testes (6-8 months, $n=15)$ by means of quantitative RT-PCR showed that levels of both TRPV2 (3.375 \pm 0.257 , $p \leq 0.0001)$ and NOX2 $(6.283 \pm 1.114, p \leq 0.0001)$ presented highly significant increases with age (Figure 2D).

Moreover, we found a highly significant increase for all investigated macrophage markers (CD54: $2.521 \pm 0.415, p=0.0010 ; C D 68: 6.318 \pm 1.580, p \leq 0.0001 ; C D 74: 9.838 \pm 2.292$, $p \leq 0.0001 ; C D 206: 3.377 \pm 0.669, p=0.0002$; Figure 2E), and, as expected, also TNF$\alpha(5.341 \pm 1.158, p \leq 0.0001)$ and TIMP-1 $(4.307 \pm 1.205, p=0.0292)$ were significantly increased. However, CXCL-1 was not changed (Figure 2F).

\subsection{TRPV2, Macrophage and Inflammation Markers in a Genotypic Comparison}

For a better appreciation of the differences between the observed findings in testes from young and old WT and $\mathrm{AROM}^{+}$mice, on the one hand, quantitative RT-PCR datasets were re-analyzed comparing coeval animals of both genotypes (Figure S3) and on the other hand, datasets of proteomes from both WT and $\mathrm{AROM}^{+}$testes of 11 month-old animals subjected to mass spectrometry were re-analyzed and screened for macrophage and inflammation markers, TRPV2 and ROS generating enzymes (Figure 3).

In testes from young $\mathrm{AROM}^{+}$animals, TRPV2 mRNA expression levels were found to be significantly higher compared to coeval WT mice $(2.464 \pm 0.365, p=0.0029)$, and the difference between the two genotypes was further strongly augmented with the increasing age $(5.217 \pm 0.397, p \leq 0.0001)$. In terms of testicular NOX2, there were significantly higher levels of the ROS producing enzyme in $\mathrm{AROM}^{+}$mice compared to coeval WT mice (Figure S3A), both in young $(3.049 \pm 0.602, p=0.0210)$ and old animals $(8.604 \pm 1.526$, $p \leq 0.0001)$.

Comparison of macrophage marker expression levels in testes from young WT and $\mathrm{AROM}^{+}$animals revealed significantly higher levels of CD54 $(2.772 \pm 0.431, p \leq 0.0001)$ and CD68 (3.441 $\pm 0.304, p \leq 0.0001$ ), but not of CD74 and CD206. However, in old animals all analyzed macrophage markers showed significantly higher expression levels in $\mathrm{AROM}^{+}$animals compared to coeval WT mice (CD54: $4.062 \pm 0.539, p \leq 0.0001 ; \mathrm{CD} 68$ : 
$18.610 \pm 4.654, p \leq 0.0001 ; C D 74: 6.488 \pm 1.511, p=0.0022 ; C D 206: 2.399 \pm 0.475, p=0.0176$; Figure S3B).

A

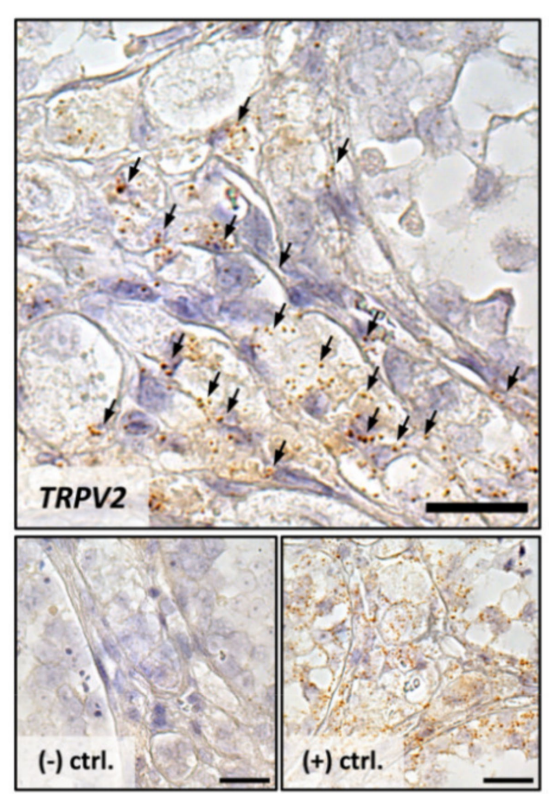

B

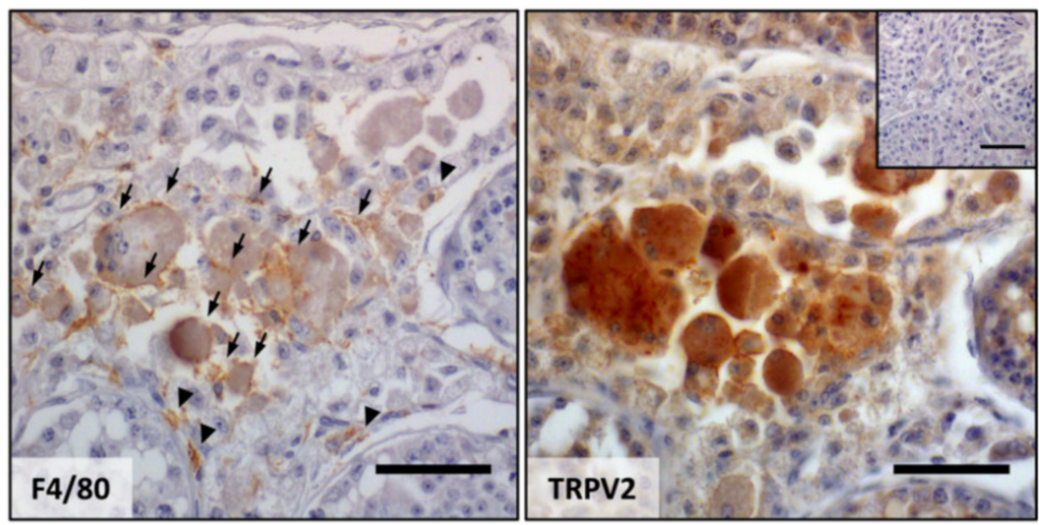

C

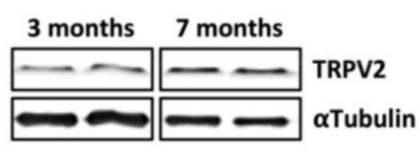

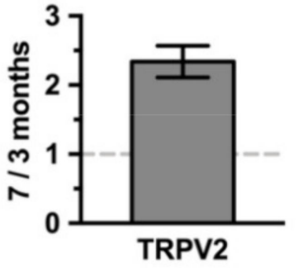

D

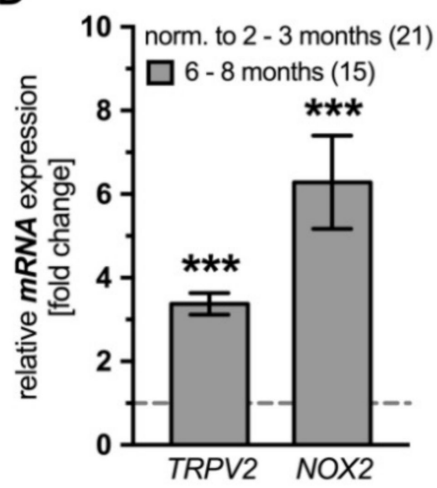

$\mathbf{E}$

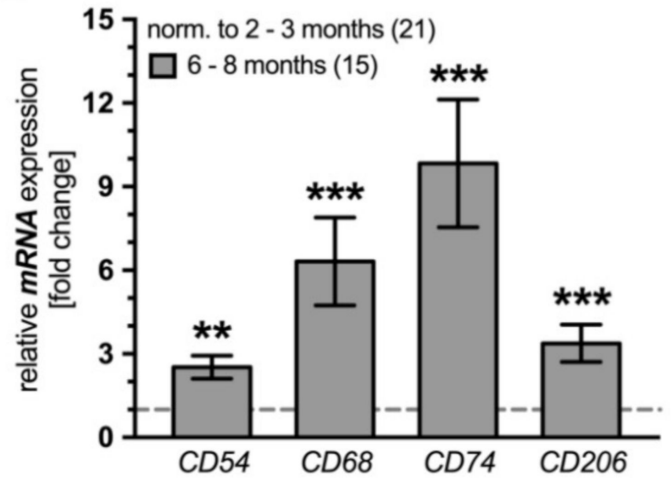

$\mathbf{F}$

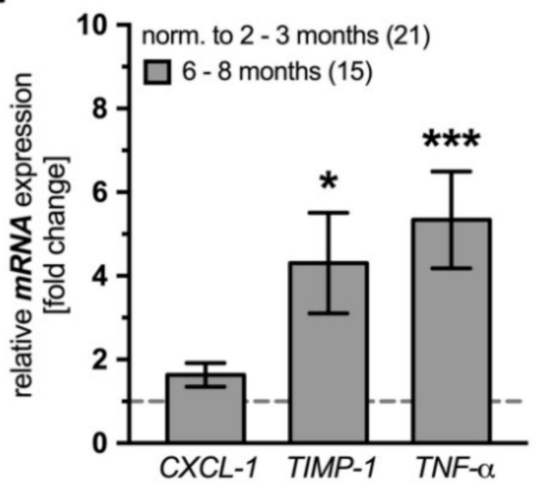

Figure 2. Expression profile of TRPV2, NOX2, macrophage and inflammation markers in $\mathrm{AROM}^{+}$testes. (A) Testicular sections of 10 month-old $\mathrm{AROM}^{+}$mice subjected to TRPV2 in situ hybridization (upper panel) revealed strong and punctuated staining mainly in the interstitial space (arrows). The negative control (lower left panel, (-) ctrl.) showed no signals, but the positive control (lower right panel, (+) ctrl.) did. Scale bar is $50 \mu \mathrm{m}$. (B) Consecutive testicular sections of 10 month-old $\mathrm{AROM}^{+}$animals subjected to immunohistochemistry using antibodies against the general murine macrophage marker F4/80 (left panel) and TRPV2 (right panel) revealed strong membrane-associated F4/80 staining in normal-sized and hyperplastic cells in the interstitial space (arrows), with some faint staining also within or close to the peritubular wall (arrow heads). TRPV2 showed a strong membrane-associated signal in the interstitial space, in both normal-sized and hyperplastic cells, whereas peritubular walls remained clear of any signal. The insert represents a negative control with the $1^{\text {st }}$ antibody omitted. Scale bar is $50 \mu \mathrm{m}$. (C) TRPV2 immunoblotting of whole testis lysates of young ( 3 months, $\left.n=2\right)$ and old $\mathrm{AROM}^{+}$animals ( 7 months, $\left.n=2\right)$ showed that bands at the expected size and quantification confirmed increased expression levels on the protein level. $\alpha$ Tubulin was used as a loading control. (D-F) The mRNA of whole testis lysates from young and old $\mathrm{AROM}^{+}$mice was subjected to quantitative RT-PCR to investigate the expression profile of (D) TRPV2 and NOX2, (E) macrophage and (F) inflammation markers revealing highly significant differences except for the inflammation marker CXCL-1 $(1.631 \pm 0.286, p=0.1034)$. The graphs represent the mean \pm SEM of old $\mathrm{AROM}^{+}$mice $(6-8$ months, $n=15)$ normalized to young animals (2-3 months, $n=21)$; unpaired two-tailed $t$-test, $\alpha=0.05 ;^{*} p \leq 0.05,{ }^{* *} p \leq 0.01,{ }^{* * *} p \leq 0.001$. 


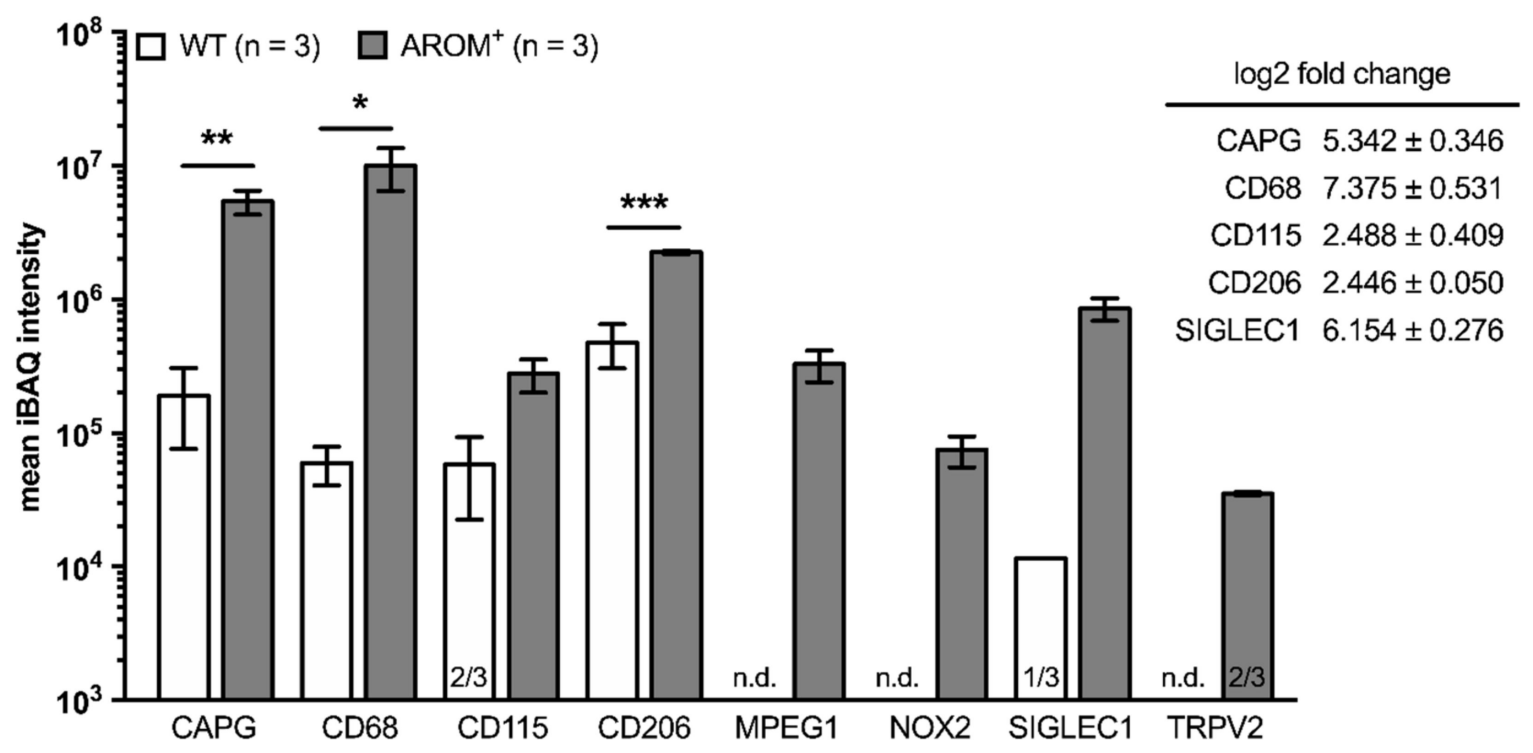

Figure 3. Mass spectrometry-based comparison of expression profiles in old $\mathrm{WT}$ and $\mathrm{AROM}^{+}$testes. Extracted proteins from testicular tissue of 11 month-old WT and $\mathrm{AROM}^{+}$animals $(n=3$, each) were subjected to mass spectrometry. The graph presents iBAQ intensities (mean \pm SEM) of detected proteins and results of statistical analysis of a genotype-dependent comparison when proteins could be detected in all replicates using an unpaired two-tailed $t$-test with $\alpha=0.05 ;{ }^{*} p \leq 0.05$, ${ }^{* *} p \leq 0.01,{ }^{* * *} p \leq 0.001$. The numbers of positive replicates other than $3 / 3$ are depicted at the bottom of each column (n.d.: not detected). The insert on the right depicts the mean differential expression of detected proteins (log2 fold change) in testes from $\mathrm{AROM}^{+}$animals compared to coeval WT animals, if calculable.

In terms of inflammation markers, already young $\mathrm{AROM}^{+}$animals featured significantly higher CXCL-1 (2.649 $\pm 0.319, p=0.0012)$, TIMP-1 $(4.787 \pm 0.502, p \leq 0.0001)$ and TNF- $\alpha$ expression levels $(2.518 \pm 0.375, p=0.0057)$ compared to coeval WT mice. An observation being even stronger in the old mice of the two genotypes (CXCL-1: $5.071 \pm 0.889$, $p=0.0007$; TIMP-1: $22.990 \pm 6.436, p=0.0002 ;$ TNF- $\alpha$ : $9.102 \pm 1.973, p \leq 0.0001$; Figure S3C), indicates the increasing severity of the inflammatory testicular phenotype with age.

In a recent study [3], proteomes from both WT and $\mathrm{AROM}^{+}$testes of 11 month-old animals ( $n=3$, each) were studied by mass spectrometry and the datasets were screened for macrophage markers, inflammation markers, TRPV2 and ROS generating enzymes (Figure 3). The macrophage markers CAPG, CD68, and CD206 were readily found in all three animals of both genotypes with the mean $\mathrm{BAQ}$ intensities being significantly higher in testes from AROM animals (CAPG: $p=0.0097$; CD68: $p=0.0484$; CD206: $p=0.0007$ ). In addition, CD115, MPEG1, and SIGLEC1 could be detected in all three analyzed $\mathrm{AROM}^{+}$ mice, while in the WT animals CD115 was only present in two out of three animals, SIGLEC1 only in one and MPEG1 was even exclusively found in $\mathrm{AROM}^{+}$mice.

Furthermore, next to MPEG1, both TRPV2 and NOX2, being the only ROS generating enzyme detected within these datasets, were exclusively found in $\mathrm{AROM}^{+}$animals by this experimental approach.

\subsection{Flow Cytometry Analysis of Testicular Macrophages from Young WT and AROM+ Mice}

To obtain an in-depth insight into the true nature of the testicular macrophages being positive for TRPV2, whole testes of young WT and $\mathrm{AROM}^{+}$mice ( 3 months, $n=3$ each) were digested, and isolated cells were subjected to the flow cytometry (FACS) analysis. $\mathrm{CD} 45^{+} \mathrm{CD} 11 \mathrm{~b}^{+} \mathrm{F} 4 / 80^{+}$macrophages were further subdivided into four subpopulations based on their CD206 and MHC II expression (CD206 ${ }^{-} \mathrm{MHC} \mathrm{II}^{-}, \mathrm{CD}^{206}{ }^{+} \mathrm{MHC} \mathrm{II}^{-}$, $\mathrm{CD}^{206}{ }^{-} \mathrm{MHC} \mathrm{II}^{+}, \mathrm{CD}^{206^{+}} \mathrm{MHC} \mathrm{II}^{+}$) and sorted (Figure 4A,C). 
A

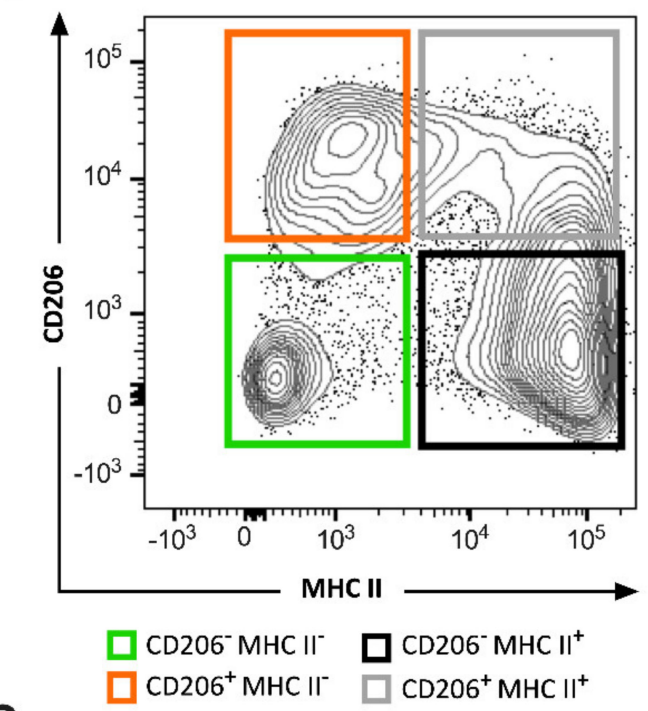

C

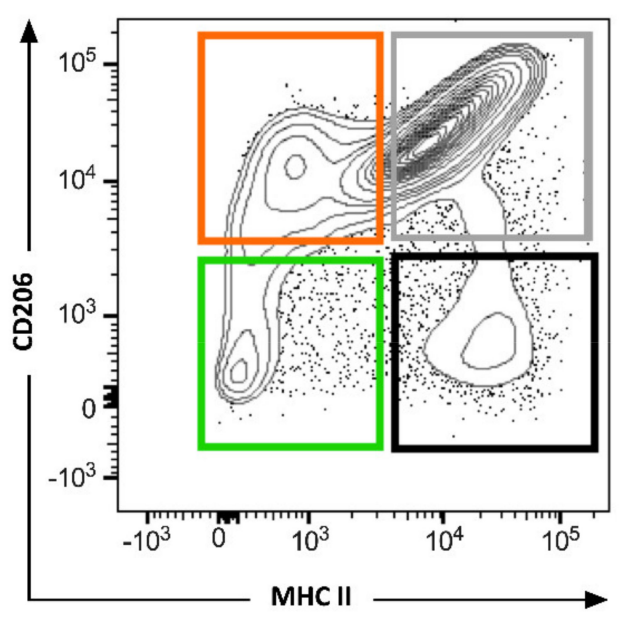

B

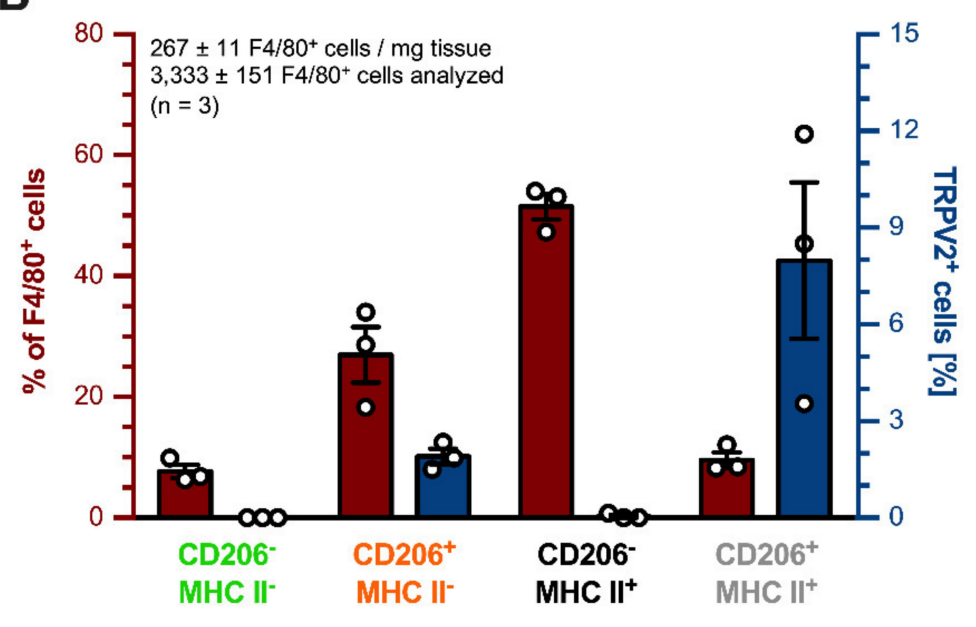

D

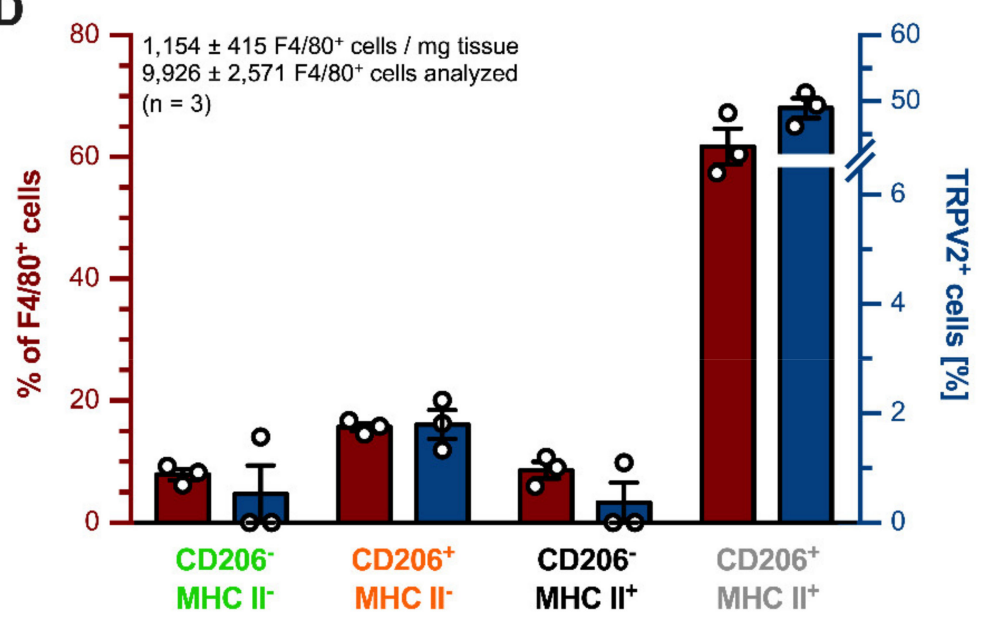

E

\begin{tabular}{|c|c|c|c|c|c|c|c|c|}
\hline subpopulation & \multicolumn{2}{|c|}{$\begin{array}{l}\text { CD206- } \\
\text { MHC II- }\end{array}$} & \multicolumn{2}{|c|}{$\begin{array}{l}\text { CD206 } \\
\text { MHC II" }\end{array}$} & \multicolumn{2}{|c|}{$\begin{array}{l}\mathrm{CD}^{206}{ }^{-} \\
\mathrm{MHC}^{+} \mathrm{II}^{+}\end{array}$} & \multicolumn{2}{|c|}{$\begin{array}{l}\mathrm{CD} 206^{+} \\
\mathrm{MHC} \mathrm{II}^{+}\end{array}$} \\
\hline WT vs. AROM ${ }^{+}$ & $\begin{array}{c}\% \\
F 4 / 80\end{array}$ & $\begin{array}{c}\% \\
\text { TRPV2 }\end{array}$ & $\begin{array}{c}\% \\
\text { F4/80 }\end{array}$ & $\begin{array}{c}\% \\
\text { TRPV2 }\end{array}$ & $\begin{array}{c}\% \\
\text { F4/80 }\end{array}$ & $\begin{array}{c}\% \\
\text { TRPV2 }\end{array}$ & $\begin{array}{c}\% \\
F 4 / 80\end{array}$ & $\begin{array}{c}\% \\
\text { TRPV2 }\end{array}$ \\
\hline$p$ value & 0.8883 & $x$ & 0.0719 & 0.7729 & $<0.0001$ & $\mathrm{x}$ & $<0.0001$ & 0.0001 \\
\hline
\end{tabular}

Figure 4. Flow cytometry analysis of testicular macrophage populations of young $\mathrm{WT}$ and $\mathrm{AROM}^{+}$mice. Cells from 3 month-old WT and $\mathrm{AROM}^{+}$testes $(n=3$, each) were isolated, processed for FACS analysis and sorted for macrophage markers $\left(\mathrm{CD} 45^{+} \mathrm{CD} 11 \mathrm{~b}^{+} \mathrm{F} 4 / 80^{+}\right)$, and further divided by $\mathrm{CD} 206$ and MHC II expression. TRPV2 expression was quantified within the resulting subpopulations. (A,C) Representative two-dimensional plots of a WT (A) and $\mathrm{AROM}^{+}$animal (C), showing the four subpopulations depending on their CD206 and MHC II expression level (green-CD206 ${ }^{-} \mathrm{MHC} \mathrm{II}^{-}$, orange-

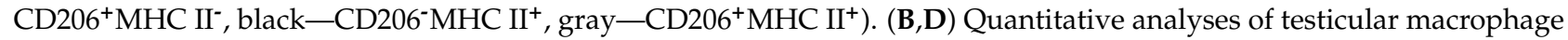
subpopulations in $\mathrm{WT}$ and $\mathrm{AROM}^{+}$mice. The percentages of total $\mathrm{F} 4 / 80^{+}$cells (red axis), and TRPV2 ${ }^{+}$cells within these particular subpopulations (blue axis) are shown. The graphs represent mean \pm SEM. (E) Results of statistical analysis ( $p$ values) of the particular subpopulations (\% of $\mathrm{F} 4 / 80^{+}$) and the corresponding percentage of $\mathrm{TRPV}^{+}$cells (TRPV2 ${ }^{+}$cells [\%]) within these subpopulations of $\mathrm{WT}$ and $\mathrm{AROM}^{+}$animals, using an unpaired two-tailed $t$-test, $\alpha=0.05$, where Gaussian distribution is given and proteins could be detected in all replicates (3/3).

Testes from WT animals $(n=3)$ harbored a total of $267 \pm 11 \mathrm{CD} 45^{+} \mathrm{CD} 11 \mathrm{~b}^{+} \mathrm{F} 4 / 80^{+}$ cells per mg tissue and $3333 \pm 151$ of these cells were subjected to the flow cytometry analysis. The biggest fraction of these cells could be allotted to CD206-MHC $\mathrm{II}^{+}$macrophages 
$(51.470 \pm 2.099 \%)$, followed by CD206 ${ }^{+} \mathrm{MHC}^{-}(26.970 \pm 4.605 \%), \mathrm{CD}^{-} 06^{+} \mathrm{MHC} \mathrm{II}^{+}$ $(9.583 \pm 1.260 \%)$, and CD206 ${ }^{-}$MHC II- ones $(7.677 \pm 1.107 \%$; Figure $4 \mathrm{~B}$, plotted on the left red axis). Amongst these macrophage subpopulations, the double-positive group of $\mathrm{CD}^{206^{+} \mathrm{MHC} \mathrm{II}}{ }^{+}$macrophages had the highest percentage of TRPV2 ${ }^{+}$cells with $7.893 \pm 2.424 \%$ (3/3). CD206 ${ }^{+} \mathrm{MHC} \mathrm{II}^{-}$macrophages harbored $1.903 \pm 0.241 \% \mathrm{TRPV}^{+}$cells $(3 / 3)$, whereas only in one animal (1/3) $0.140 \%$ of $\mathrm{CD}^{206^{-}} \mathrm{MHC} \mathrm{II}^{+}$macrophages were also positive for TRPV2, giving further support to the findings made on mRNA expression levels from sorted macrophages (Figure 1F). The double negative CD206-MHC II- subpopulation was bare of any TRPV $2^{+}$cells $(0 / 0)$ (Figure $4 \mathrm{~B}$, plotted on the right blue axis).

In contrast, testes from $\mathrm{AROM}^{+}$animals $(n=3)$ contained substantially more $\mathrm{CD} 45^{+} \mathrm{CD} 11 \mathrm{~b}^{+} \mathrm{F} 4 / 80^{+}$cells with $1154 \pm 415$ cells per mg tissue and $9926 \pm 2571$ cells were subjected to the flow cytometry analysis revealing a drastically shifted distribution of macrophage subpopulations towards the double-positive $\mathrm{CD}_{206}{ }^{+} \mathrm{MHC} \mathrm{II}^{+}$subpopulation with $61.730 \pm 2.924 \%$ of all F4 $/ 80^{+}$cells (Figure $4 \mathrm{C}$ ), and $48.970 \pm 1.488 \%$ of those being also TRPV2 ${ }^{+}(3 / 3)$. The double negative CD206 ${ }^{-} \mathrm{MHC} \mathrm{II}^{-}$subpopulation represented only $7.890 \pm 0.900 \%$ of all $\mathrm{F} 4 / 80^{+}$cells with $1.570 \%$ being also TRPV2 ${ }^{+}(1 / 3) . \mathrm{CD}^{2} 06^{+} \mathrm{MHC}$

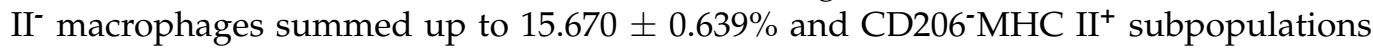
came to $8.593 \pm 1.375 \%$ of total $\mathrm{F} 4 / 80^{+}$cells. Moreover, applying also for $\mathrm{AROM}^{+}$mice, $\mathrm{CD}^{206}{ }^{+} \mathrm{MHC} \mathrm{II}^{-}$macrophages showed more TRPV2 ${ }^{+}$cells with $1.793 \pm 0.263 \%(3 / 3)$ than those macrophages being CD206 ${ }^{-} \mathrm{MHC}^{+\mathrm{II}^{+}}$with only $1.100 \%$ (1/3), respectively (Figure 4D).

For a comparison between the results obtained from these $\mathrm{CD} 45^{+} \mathrm{CD} 11 \mathrm{~b}^{+} \mathrm{F} 4 / 80^{+}$cells derived from WT and $\mathrm{AROM}^{+}$mice, datasets were statistically analyzed using a two-tailed unpaired $t$-test where Gaussian distribution was given and the corresponding protein could be detected in all three replicates of each group (Figure 4E). In terms of macrophage subpopulation composition ( $\%$ of $\mathrm{F} 4 / 80^{+}$cells), there was no significant difference in the amount of $\mathrm{CD}^{206}{ }^{-} \mathrm{MHC} \mathrm{II}^{-}(p=0.8883)$ and CD206 ${ }^{+} \mathrm{MHC}^{-} \mathrm{II}^{-}(p=0.0719)$ cells between the two genotypes. However, in $\mathrm{AROM}^{+}$animals there were significantly fewer CD206 ${ }^{-\mathrm{MHC}}$ $\mathrm{II}^{+}$macrophages ( $\left.p \leq 0.0001\right)$, but the percentage of the double-positive subpopulation of $\mathrm{CD}^{+} 06^{+} \mathrm{MHC}^{+} \mathrm{II}^{+}$cells was significantly higher in these mice $(p \leq 0.0001)$.

Expression of TRPV2 within these macrophage subpopulations (TRPV2 ${ }^{+}$cells [\%]) could only be statistically investigated for $\mathrm{CD}_{206}{ }^{+} \mathrm{MHC} \mathrm{II}{ }^{-}$and CD206 ${ }^{+} \mathrm{MHC} \mathrm{II}^{+}$cells, since TRPV2 could be found in all the animals examined. For CD206 ${ }^{+} \mathrm{MHC} \mathrm{II}^{-}$macrophages, there was no significant difference in TRPV2 ${ }^{+}$cells between the two genotypes $(p=0.7729)$, while in $\mathrm{AROM}^{+}$animals the double-positive $\mathrm{CD} 206^{+} \mathrm{MHC} \mathrm{II}{ }^{+}$cells included significantly more TRPV $2^{+}$macrophages $(p=0.0001)$ compared to coeval WT mice.

\subsection{TRPV2 in Rescue Experiments of AROM ${ }^{+}$Mice}

In previous studies [6,42], the altered endocrine phenotype of $\mathrm{AROM}^{+}$testis was rescued by administration of an aromatase inhibitor or by cross-breeding with estrogen receptor $\alpha$ knock-out $(\mathrm{ER} \alpha \mathrm{KO})$ animals. We examined whether under these conditions elevated TRPV2 and NOX2 but also macrophage and inflammation markers are reverted.

Briefly, 1 month-old WT and $\mathrm{AROM}^{+}$animals were exposed to an aromatase inhibitor (finrozole) or corresponding placebo control (carboxylmethyl-cellulose) for 6 weeks and mRNA was isolated from whole testis lysates after sacrifice of the animals for further analysis.

The data revealed that administration of the aromatase inhibitor caused only slight, but partially statistically significant changes in WT animals $(n=7)$, i.e., a slight increase in CD206 mRNA expression $(1.825 \pm 0.183, p=0.0153)$, whereas none of the other investigated markers showed significant changes compared to the placebo-treated WT animals $(n=7)$.

The analysis of placebo-treated $\mathrm{AROM}^{+}$animals $(n=7)$ revealed expected results with significantly increased expression levels of TRPV2 and NOX2, as well as the majority of the macrophage and inflammation markers (TRPV2: $1.692 \pm 0.094, p=0.0369$; NOX2: $3.094 \pm 0.532, p=0.0078 ; C D 54: 3.940 \pm 0.602, p=0.0211 ; C D 68: 2.562 \pm 0.244, p \leq 0.0001$; CD206: $2.113 \pm 0.219, p=0.0060$; TIMP-1: $1.722 \pm 0.150, p=0.0004$; TNF- $\alpha: 4.026 \pm$ $0.841, p=0.0014)$. However, $C D 74(0.533 \pm 0.069, p=0.0323)$ was significantly decreased 
and CXCL-1 was indistinguishable from the placebo-treated WT animals $(2.185 \pm 0.333$, $p=0.1204$;).

The inhibitor treatment had a strong impact on $\mathrm{AROM}^{+}$animals $(n=6)$ and, except for CD206 (1.350 $\pm 0.172, p=0.0491)$, levels of all markers were significantly indistinguishable from the ones of placebo-treated WT (TRPV2: $0.867 \pm 0.181, p=0.3956$; NOX2: $1.731 \pm 0.329, p=0.2692 ; C D 54: 2.160 \pm 0.332, p=0.1934 ; C D 68: 0.778 \pm 0.055, p=0.9942 ;$ CD74: $0.863 \pm 0.143, p=0.2712 ; C X C L-1: 0.700 \pm 0.122, p=0.3389 ;$ TIMP-1: $0.963 \pm 0.148$, $p=0.7161 ;$ TNF- $\alpha: 1.453 \pm 0.402, p=0.6045 ;$ Figure $5 \mathrm{~A}-\mathrm{C})$.

A

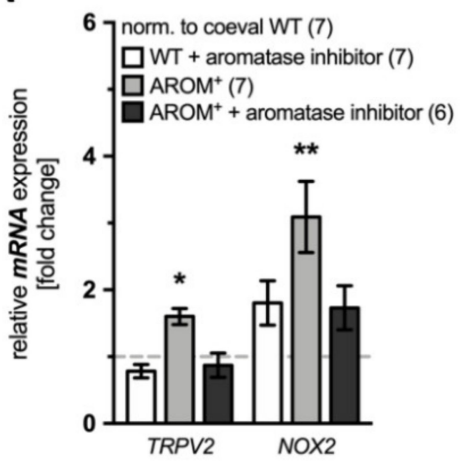

D

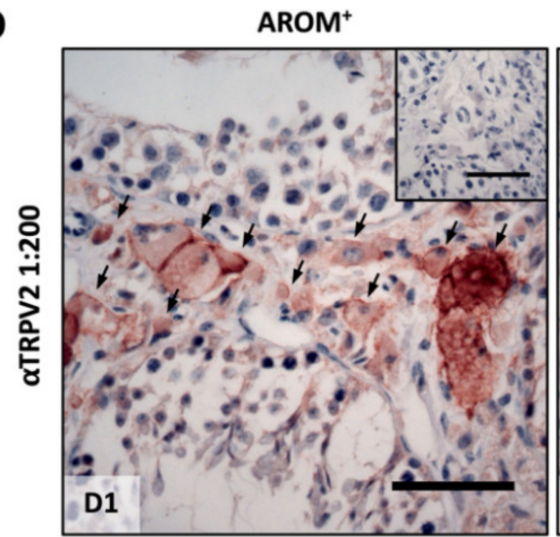

B
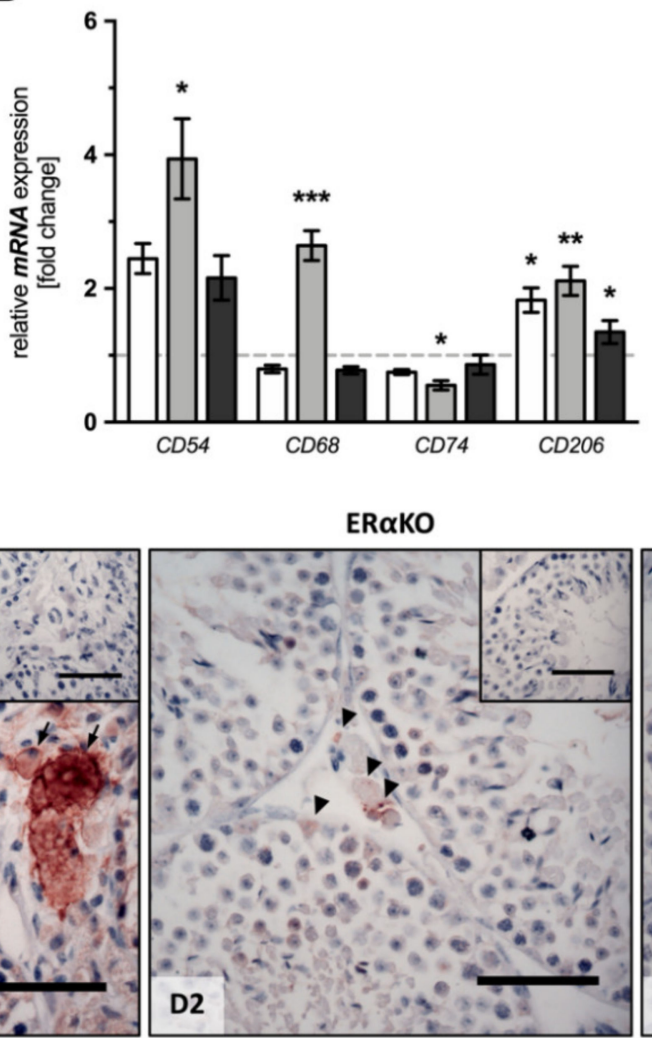

C

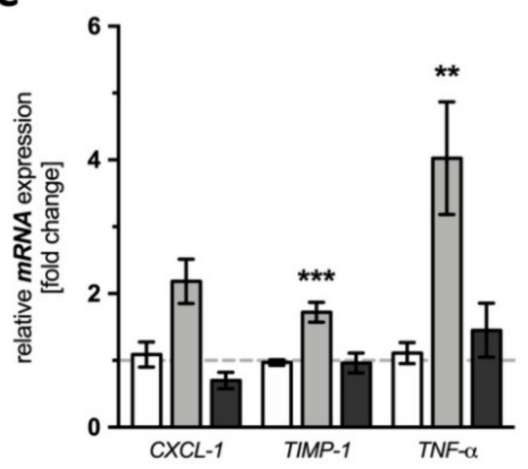

AROM $^{+} x$ ER $\alpha$ KO

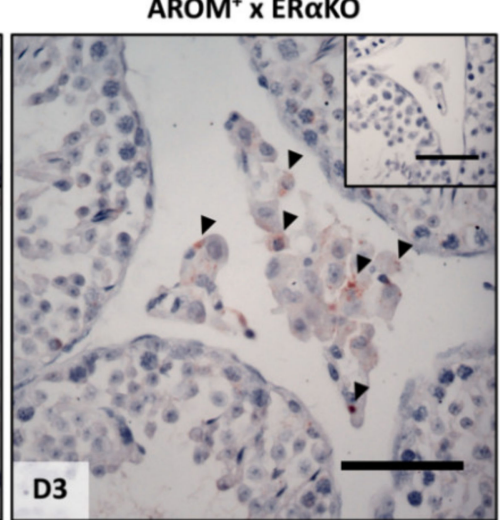

Figure 5. Rescue experiments of $\mathrm{AROM}^{+}$mice prevent TRPV2 increases. (A-C) One month-old WT and $\mathrm{AROM}^{+}$mice were treated with an aromatase inhibitor or with corresponding placebo for 6 weeks and whole testes were analyzed for their mRNA expression profile of (A) TRPV2 and NOX2, (B) macrophage and (C) inflammation markers. The graphs represent mean \pm SEM of inhibitor-treated WT ( $n=7$, white bars) and $\mathrm{AROM}^{+}$mice treated with either placebo $(n=7$, light grey bars) or aromatase inhibitor ( $n=6$, dark grey bars) compared to coeval placebo-treated WT animals $(n=7)$; unpaired two-tailed $t$-test, $\alpha=0.05 ;{ }^{*} p \leq 0.05,{ }^{* *} p \leq 0.01, * * * p \leq 0.001$. (D) Immunohistochemistry for TRPV2 performed on testicular sections from 9 month-old $\mathrm{AROM}^{+}$(D1), $\mathrm{ER} \alpha \mathrm{KO}$ (D2) and $\mathrm{AROM}^{+}$mice crossbred with $\mathrm{ER} \alpha \mathrm{KO}$ mice (D3) revealed strong positive signals in the interstitial space of $\mathrm{AROM}^{+}$mice mainly membranous in normal-sized and hyperplastic cells (arrows), but only very weak and faint staining within the interstitial space of $\mathrm{ER} \alpha \mathrm{KO}$ and in $\mathrm{AROM}^{+}$mice crossbred with $\mathrm{ER} \alpha \mathrm{KO}$ animals, with a rather punctuated pattern (arrow heads). The inserts depict corresponding controls with the omitted $1^{\text {st }}$ antibody. Scale bar is $50 \mu \mathrm{m}$.

As shown before, crossbreeding of $\mathrm{AROM}^{+}$mice with mice lacking estrogen receptor $\alpha$ recovered the normal histological appearance of testicular sections without hyperplastic cells in the interstitial space and normal spermatogenesis. In this study, the strong TRPV2immunoreactive staining in the interstitial space localized to the cellular membrane in 9 month-old $\mathrm{AROM}^{+}$animals (Figure 5D-D1), turned to only a weak and punctuated staining in the interstitial space of $\mathrm{AROM}^{+}$mice crossed with ER $\alpha \mathrm{KO}$ mice (Figure 5D-D3), similar to that observed in ER $\alpha \mathrm{KO}$ animals (Figure 5D-D2). 


\subsection{TRPV2 in Adrenals and Brain}

When we explored mRNA levels of TRPV2 in the adrenal, another steroid-producing organ, from young and old WT and $\mathrm{AROM}^{+}$animals $(n=3$, each), we found that its levels slightly but not significantly increase with age in both WT $(2.597 \pm 0.618, p=0.0613)$ and in $\mathrm{AROM}^{+}$mice $(2.997 \pm 1.014, p=0.1203)$ compared to the corresponding coeval animals. Expression levels of TRPV2 in the immune-privileged organ brain, while readily detectable, did not change with age, neither in WT $(1.210 \pm 0.079, p=0.0573)$, nor in $\mathrm{AROM}^{+}$animals (1.277 $\pm 0.150, p=0.1365)$. Taken together, the significantly increased expression levels of TRPV2 in the testis of old $\mathrm{AROM}^{+}$mice (3.141 $\left.\pm 0.538, p=0.0163\right)$ compared to young ones, in contrast to WT animals showing no changes (1.310 $\pm 0.241, p=0.2687)$, further confirm the testis-specificity of this observation (Figure S5).

\section{Discussion}

This study describes, for the first time, the expression pattern of the mysterious cation channel TRPV2 in murine testis with special regard to macrophages in the case of WT and the well-established model for male infertility $\mathrm{AROM}^{+}$, taking into account age-related changes. The results indicate that although TRPV2 is expressed by testicular macrophages in the WT mouse testis, expression levels are low and hence this channel likely is not to be considered a major factor involved in the regulation of testicular function during adult life and aging. However, the results of the analysis of testes from $\mathrm{AROM}^{+}$animals imply that the population of TRPV $2^{+}$testicular macrophages massively increases with age induced by a misbalance of estrogen/androgen levels. It is likely that the testicular TRPV2 ${ }^{+}$ macrophages are part of an inflammatory cascade in the testes of $\mathrm{AROM}^{+}$and thereby are involved in the development of infertility.

TRPV2 could be detected and localized to interstitial cells of WT mice. However, the levels of TRPV2 were low, and the nature of the positive cells could not be readily identified by in situ hybridization studies. However, FACS isolation and subsequent RT-PCR showed that the TRPV2 ${ }^{+}$cells are mainly interstitial CD206 ${ }^{+}$macrophages rather than peritubular MHC II ${ }^{+}$macrophages.

Pilot studies, namely the evaluation of organotypic incubations of mouse testes, indicated that in the presence of CB1 and CB2 blockers activation of testicular TRPV2 by CBD caused a detectable pro-inflammatory response, e.g., elevation of CXCL-1. The lack of more specific pharmacological tools, which would allow one to activate or block TRPV2 selectively, prevented us from further studies.

The magnitudes of the expression levels of TRPV2 and all analyzed macrophage or inflammation markers were not statistically significantly different in older WT animals. Of note, expression levels of the superoxide-producing enzyme NOX2 increased, albeit only numerically with age. It may be a source of ROS, which have recently been described as natural activators and sensitizers of TRPV2 [28]. The role of NOX2 (and NOX1) was also reported to be critical for the differentiation of monocytes to macrophages and the polarization of M2 type but not M1 type macrophages [43]. In immune cells, including macrophages [44], such a mechanism of activation is very likely responsible for the regulation of macrophage functionality. Thus, the macrophage number may increase in the aged rodent testis [17], and their phenotype may undergo alteration, yet an active role of TRPV2 in the testes of old mice requires further investigation.

$\mathrm{AROM}^{+}$testes are characterized, amongst other changes, by increased numbers of macrophages [1]. They have not yet been fully examined but the expression of CD68 and high TNF- $\alpha$ implicate a polarization towards M1 macrophages [15]. The high phagocytotic activity can be concluded from the observation that the macrophages engulf other cells, including Leydig cells [42]. We extended previous studies on this topic. We found that TRPV2 was readily detected in testes of $\mathrm{AROM}^{+}$mice already at young adult ages. A FACS analysis performed with young mice revealed the unique nature of these cells. They constitute a group of $\mathrm{CD}_{206} \mathrm{MHC} \mathrm{II}^{+}$cells, which is almost absent in normal WT mouse testis. Hence, the hormonal imbalances in the testes of these mice likely had initiated changes 
in the macrophage populations, resulting in the acquisition of this unique population. Whether the changes involve recruitment of a new macrophage population, as recently suggested to occur after radiation or infection [19] and whether or to which degree the factors of the local environment contribute to these changes [15], remain to be investigated.

The expression of TRPV2 and NOX2 in the $\mathrm{AROM}^{+}$testes further increased with age. As mentioned, NOX2 is reported to be critical for the differentiation of monocytes to macrophages [43], but it is also a source of ROS and could thereby activate and sensitize TRPV2. The analysis of expression profile of $\mathrm{AROM}^{+}$testes gave hints of both, higher NOX2 expression levels and more pro-inflammatory macrophages (evidenced, e.g., by higher inflammatory factors). The FACS analysis could not be readily performed in older animals, due to the altered and overall remodeled structure of the testes. Still, the evaluation of proteomic data of old animals indicated that several other macrophage markers increase in $\mathrm{AROM}^{+}$animals (i.e., CAPG, CD68, CD206, MPEG1, and SIGLEC1). Furthermore, TRPV2 and NOX2 were exclusively found in $\mathrm{AROM}^{+}$animals by this experimental approach, arguing against a role in normal aging in WT (see above) and for a role in $\mathrm{AROM}^{+}$.

Changes in testicular morphology and macrophage accumulation are initiated by hormonal imbalances and estrogen receptor $\alpha$ action, although the exact chain of events is unknown. It is assumed that increased estradiol levels stimulate Leydig cells to produce growth arrest-specific 6 (GAS6), which mediates phagocytosis of apoptotic cells by bridging cells with surface-exposed phosphatidylserine (PS) to macrophage receptors [45]. In general agreement with this assumption, we found that both the aromatase inhibitor treatment, as well as crossings of $\mathrm{AROM}^{+}$with $\mathrm{ER} \alpha \mathrm{KO}$, not only, as expected, rescued the infertile phenotype $[6,42]$ and reverted macrophage and inflammation markers, but also reduced TRPV2 and NOX2 levels.

$\mathrm{AROM}^{+}$mice have been studied for several years and changes in prostate, spleen, and testes were described. Higher plasma immunoglobulin levels in $\mathrm{AROM}^{+}$mice are due to distinct changes in the spleen [4] and may indicate a generally altered immunological situation. Prostatitis and prostatic pre-malignancy occur in an age-dependent manner. Next to $\mathrm{F} 4 / 80^{+}$macrophages several other immune cell types were described in prostate. Increased macrophage numbers were first observed in the prostate of $\mathrm{AROM}^{+}$mice at the age of 30 weeks and then increased with the advanced lifespan. In comparison, in $\mathrm{AROM}^{+}$ animals, testicular macrophages and testicular alterations are detectable at about 2 months of age, i.e., much earlier. Together with the other changes mentioned, this suggests organspecific changes. We further monitored TRPV2 levels in adrenals and brains of male $\mathrm{AROM}^{+}$and WT animals (see Supplementary Materials, Figure S5). We chose the brain since similar to the testis, it is an immune-privileged organ. However, we did not find any changes in TRPV2 expression in $\mathrm{AROM}^{+}$compared to WT and no evidence for ageassociated alterations either. In contrast, in steroid-producing adrenals, TRPV2 increased with age but in a similar fashion in both, $\mathrm{WT}$ and $\mathrm{AROM}^{+}$mice. The results indicate that in the adrenal, which is similar to the testis produces steroids, age is the major factor in the induction of TRPV2. The results require additional studies, but taken together, the distinct changes in the mentioned organs indicate that changes in TRPV2 and macrophages occur in a highly organ-specific way.

In summary, our study further defines the phenotypes of testicular macrophages in the mouse. TRPV2 ${ }^{+}$macrophages normally reside in the mouse testis, yet are of limited number and do not change significantly with age. Hormonal imbalances, however, initiate a chain of events, in which the number of TRPV2 ${ }^{+}$macrophages increases. This situation causes the appearance of a CD206 ${ }^{+} \mathrm{MHC} \mathrm{II}{ }^{+}$subpopulation of TRPV2 ${ }^{+}$macrophages, which appear to be part of the inflammatory events in $\mathrm{AROM}^{+}$animals and may play roles in testicular dysfunction and infertility. 


\section{Materials and Methods}

\subsection{Animals}

For this study, animals of the well-established mouse model AROM ${ }^{+}$(human P450arom transgene expressed under the ubiquitin $C$ promotor) with the corresponding WT littermates were used and age-grouped for different approaches. Moreover, 1 month-old WT and $\mathrm{AROM}^{+}$animals either treated with placebo $(5 \mathrm{mg} / \mathrm{mL}$ carboxylmethyl-cellulose in deionized water, Tamro Ltd., Vantaa, Finland) or $10 \mathrm{mg} / \mathrm{kg}$ aromatase inhibitor, finrozole (MPV-2213ad, Hormos Medical Ltd., Turku, Finland) for 6 weeks were included into this study. Further, estrogen receptor $\alpha$ knock-out mice, ER $\alpha \mathrm{KO}$, and $\mathrm{ER} \alpha \mathrm{KO}$ crossbred with $\mathrm{AROM}^{+}$animals were histologically investigated. In addition to the phenotypic control (cryptorchidism, smaller and brownish testes), the expression of the hP450 transgene (hCYP19A1) in $\mathrm{AROM}^{+}$mice was verified by means of PCR. The generation and treatment of these genetically modified mice has been described in detail elsewhere [1,2,6,7,41,42,46]. The animals had free access to soy-free food pellets (SDS; Witham, Essex, England) and tap water and were handled in accordance with the institutional animal care policies of the University of Turku (Turku, Finland).

\subsection{Immunohistochemistry and In Situ Hybridization of Testicular Sections}

After antigen retrieval using $10 \mathrm{mM}$ citrate buffer at $\mathrm{pH}$ 6, sections from Bouin's solution-fixed and paraffin embedded mouse testicular samples of all the above-mentioned genotypes- $\mathrm{AROM}^{+}, \mathrm{ER} \alpha \mathrm{KO}$, crossbreeding of these and corresponding WT animals, respectively-were immunohistochemically investigated for the presence of TRPV2 using a polyclonal antibody produced in rabbit (1: 400; HPA044993; Sigma-Aldrich, St. Louis, $\mathrm{MO}$, USA). Additionally, consecutive testicular sections of $\mathrm{AROM}^{+}$and the corresponding WT animals were scanned for the murine macrophage marker F4/80 (monoclonal antibody produced in rat; 1: 50; MCA497; AbD Serotec, Puchheim, Germany). Accordingly, biotinylated goat- $\alpha$-rabbit (1: 2500; BA-1000; Vector Laboratories, Inc., Burlingame, CA, USA) and goat- $\alpha$-rat (1: 1000; AB_2338179; Jackson Immuno Research Laboratories, Inc., Ely, Cambridgeshire, UK) secondary antibodies were used, followed by application of an avidin-biotin-complex peroxidase (ABC, Vector Laboratories, Inc. Burlingame, CA, USA) and DAB (Sigma-Aldrich, St. Louis, MO, USA). Primary antibodies omitted, non-immune serum or pre-adsorbed antibody (1: 100; APrEST83822, Sigma-Aldrich, St. Louis, MO, USA) served as negative controls. TRPV2 in situ hybridization was performed on PFAfixed $(10 \%)$ and paraffin embedded testicular sections from 2 and 10 month-old $\mathrm{AROM}^{+}$ and corresponding WT littermates using the RNAscope 2.5 HD-Brown Assay (ACD, Inc., Newark, NJ, USA) with probes against murine TRPV2 (Cat No. 522811), bacterial DapB as negative control [(-) ctrl.] and PPIB as positive control [(+) ctrl.] in accordance to the user manual. Sections from both immunohistochemistry and in situ hybridization were slightly counterstained with hematoxylin.

\subsection{Western Blot}

Protein was isolated from bisected testes of young ( 3 months, $n=2)$ and old $\mathrm{AROM}^{+}$ animals ( 7 months, $n=2)$ and the corresponding WT littermates $(n=2$, each) by disruption of the tissue using lysing tubes containing ceramic beads (Lying Matrix D; MP BiomedicalsTM; Irvine, CA, USA) and RIPA buffer supplemented with protease and phosphatase inhibitors (A32959; Thermo Fisher Scientific Inc., Waltham, MA, USA) in adequate volumes in a tissue homogenizer (FastPrep-24TM 5G; MP BiomedicalsTM; Irvine, CA, USA) with $2-3$ cycles at $6.0 \mathrm{~m} / \mathrm{s}$ speed for $120 \mathrm{~s}$ with pauses of $2 \mathrm{~min}$ on ice, followed by sonification and centrifugation at 13,000 rpm for $15 \mathrm{~min}$. The sample concentration was measured by Lowry assay (DCTM Protein Assay; Bio-Rad Laboratories, Inc., Hercules, CA, USA), and equal amounts of protein $(10 \mu \mathrm{g} /$ lane $)$ were loaded. The membrane was incubated with a polyclonal TRPV2 antibody (1: 600; HPA044993; Atlas Antibodies, Stockholm, Sweden) at $4{ }^{\circ} \mathrm{C}$ over-night and a monoclonal $\alpha$ Tubulin antibody (1: 10,000; ab52866; Abcam, Cambridge, UK) for $1 \mathrm{~h}$ at room temperature, both produced in rabbit. An IRDye 
$800 \mathrm{CW}$ secondary antibody donkey- $\alpha$-rabbit (1: 10,000; 926-32213; Li-COR Biosciences, Lincoln, NE, USA) was used and bands were detected with the Odyssey CLx imaging system (Li-COR Biosciences, Lincoln, NE, USA). Intensities were measured, background subtracted and normalized to $\alpha$ Tubulin.

\subsection{Quantitative RT-PCR}

Disruption of testicular, adrenal, and brain tissue, followed by isolation of mRNA, was done using the RNeasy Plus Universal Mini Kit (Qiagen, Hilden, Germany) following the manufacturer's protocol. The quantity of mRNA was measured using a spectrophotometrical approach (NanoDrop 2000c, Thermo Fisher Scientific Inc.) and the purity of isolated RNA was monitored by the $260 / 280$ ratio. After that, mRNA was subjected to reverse transcription (SuperScriptTM II Reverse Transcriptase; Invitrogen, Carlsbad, CA, USA). Then, 4-10 ng cDNA were used for quantitative RT-PCR (LightCycler $96^{\circledR}$ System, Roche Diagnostics, Penzberg, Germany) using the QuantiFast SYBR Green PCR kit (Qiagen, Hilden, Germany). Ribosomal protein L19 (L19) served as an internal control and was used for normalization. The statistical analysis was performed on the $\Delta \mathrm{Cq}$ values of each animal of treatment (for further details, see Section 4.9) and data are presented as changes in gene expression relative to the corresponding control group according to the $2^{-\Delta \Delta \mathrm{Cq}}$ method, as described elsewhere [47]. PCR products were loaded on a $2 \%$ agarose gel supplemented with Midori Green Advance DNA stain (Nippon Genetics Europe, Düren, Germany) for visualization, then separated, eluted, and sent for sequencing to verify their identity (GATC, Konstanz, Germany). Nucleotide sequences of the utilized primers and the size of the corresponding PCR products are given in Table 1.

Table 1. Oligonucleotide primer sequences and corresponding amplicon sizes.

\begin{tabular}{|c|c|c|c|}
\hline Gene & Reference ID & Nucleotide Sequence & Amplicon Size (bp) \\
\hline hСҮР19A1 & NM_000103 & $\begin{array}{c}5^{\prime} \text {-GCT ACC CAG TGA AAA AGG GGA-3' } \\
5^{\prime} \text {-GCC AAA TGG CTG AAA GTA CCT AT- } 3^{\prime}\end{array}$ & 140 \\
\hline L19 & NM_009078.2 & $\begin{array}{c}5^{\prime} \text {-AGG CAT ATG GGC ATA GGG AA-3' } \\
5^{\prime} \text {-CC ATG AGG ATG CGC TTG TTT-3 } 3^{\prime}\end{array}$ & 199 \\
\hline CD54 & NM_010493.3 & $\begin{array}{l}5^{\prime}-\text { TGG AGA CGC AGA GGA CCT TA-3' } \\
5^{\prime} \text {-CAG TGT GAA TTG GAC CTG CG-3' }\end{array}$ & 182 \\
\hline CD68 & NM_009853.1 & $\begin{array}{l}\text { 5'-CCA GCT GTT CAC CTT GAC CT-3' } \\
5^{\prime} \text {-AGA GGG GCT GGT AGG TTG AT-3' }\end{array}$ & 208 \\
\hline CD74 & NM_001042605.1 & $\begin{array}{l}5^{\prime} \text {-GCC ACC ACT GCT TAC TTC CT-3' } \\
5^{\prime} \text {-GTT CTT CAC AGG CCC AAG GA-3' }\end{array}$ & 198 \\
\hline CD206 & NM_008625.2 & $\begin{array}{l}\text { 5'-GAG CCC ACA ACA ACT CCT GA-3' }^{\prime} \\
5^{\prime} \text {-TCG CCA GCT CTC CAC CTA TA-3 }{ }^{\prime}\end{array}$ & 157 \\
\hline COX2 & NM_011198.4 & $\begin{array}{l}\text { 5'-CTT CGG GAG CAC AAC AGA GT-3' }^{\prime} \\
5^{\prime} \text {-TTC AGA GGC AAT GCG GTT CT-3' }\end{array}$ & 225 \\
\hline CXCL-1 & NM_008176.3 & $\begin{array}{l}5^{\prime} \text {-AGT TCC AGC ACT CCA GAC TC-3' } \\
5^{\prime} \text {-AGT GTG GCT ATG ACT TCG GT-3' }\end{array}$ & 246 \\
\hline CXCL-2 & NM_009140.2 & $\begin{array}{l}5^{\prime}-\text { TCA ATG CCT GAA GAC CCT GC-3' } \\
5^{\prime}-\text { TTT GAC CGC CCT TGA GAG TG-3' }\end{array}$ & 119 \\
\hline$I L-1 \beta$ & NM_008361.3 & 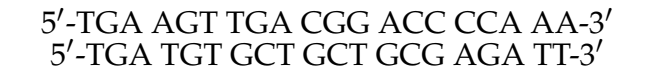 & 101 \\
\hline$I L-6$ & NM_031168.2 & 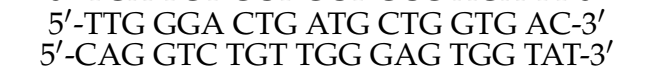 & 91 \\
\hline$M C P-1$ & NM_011333.3 & 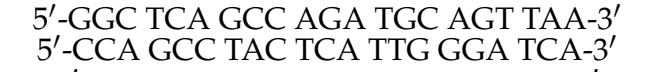 & 80 \\
\hline TIMP-1 & NM_001044384.1 & 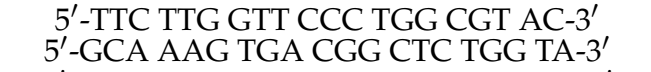 & 191 \\
\hline$T N F-\alpha$ & NM_013693.3 & 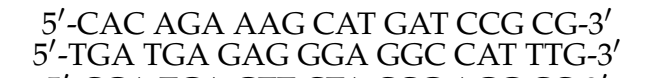 & 209 \\
\hline TRPV2 & NM_011706.2 & 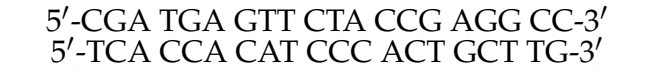 & 206 \\
\hline NOX2 & NM_007807.5 & $\begin{array}{c}5^{\prime} \text {-GAG GTT GGT TCG GTT TTG GC-3' } \\
5^{\prime} \text {-CAG GAG CAG AGG TCA GTG TG-3' }\end{array}$ & 191 \\
\hline
\end{tabular}




\subsection{Mass Spectrometry}

\subsubsection{Sample Preparation}

Approximately $1 \mathrm{mg}$ of tissue was incised from 11 month-old WT and $\mathrm{AROM}^{+}$mice testis $(n=3$, each). The tissues were homogenized manually using Micro-homogenizers, PP (Carl Roth GmbH+Co. KG, Karlsruhe, Germany) and proteins were extracted using the iST Sample Preparation Kit (PreOmics, Martinsried, Germany) using the manufacturer's protocol. Briefly, tissues were lysed and subsequently sheared to get rid of DNA and other interfering molecules followed by incubation with Trypsin at $37^{\circ} \mathrm{C}$ for $2.5 \mathrm{~h}$. The resulting peptides were subsequently desalted, purified, and re-dissolved in $10 \mu \mathrm{L}$ 'Load' solution after drying completely in a speed vac.

\subsubsection{Mass Spectrometry Measurements}

Reversed phase HPLC separation of peptides was performed on an Ultimate 3000 nanoLC system (Thermo Fisher Scientific Inc., Waltham, MA, USA). In addition, $5 \mu \mathrm{L}$ of the solution was loaded onto the analytical column $(120 \times 0.075 \mathrm{~mm}$, in the house packed with ReprosilC18-AQ, $2.4 \mu \mathrm{m}$, Dr. Maisch $\mathrm{GmbH}$, Ammerbuch-Entringen, Germany), washed for 5 min with $3 \%$ ACN containing $0.1 \% \mathrm{FA}$ at $300 \mathrm{nl} / \mathrm{min}$, and subsequently separated applying a linear gradient from $3 \%$ ACN to $40 \%$ ACN over 50 min. Peptides eluted were ionized in a nanoESI source and on line detected on a QExactive HF mass spectrometer (Thermo Fisher Scientific Inc., Waltham, MA, USA). The instrument was operated in a TOP10 method in a positive ionization mode, detecting eluting peptide ions in the $\mathrm{m} / \mathrm{z}$ range from 375 to 1600 and performing MS/MS analysis of up to 10 precursor ions. Peptide ion masses were acquired at a resolution of 60,000 (at $200 \mathrm{~m} / \mathrm{z}$ ). High-energy collision-induced dissociation (HCD) MS/MS spectra were acquired at a resolution of $15,000($ at $200 \mathrm{~m} / z$ ). All mass spectra were internally calibrated to lock masses from ambient siloxanes. Precursors were selected based on their intensity from all signals with a charge state from +2 to +5 , isolated in a $2 \mathrm{~m} / z$ window and fragmented using a normalized collision energy of $27 \%$. To prevent repeated fragmentation of the same peptide ion, the dynamic exclusion was set to $20 \mathrm{~s}$.

\subsubsection{Data Analysis}

Protein identification was performed by the MaxQuant 1.6.0.16 software package. Parent ion and fragment mass tolerances were $8 \mathrm{ppm}$ and $0.7 \mathrm{Da}$, respectively and two missed cleavages were allowed. The mouse canonical protein database from Uniprot (release June, 2018), filtered to retain only the reviewed entries was used for the searches. Regular MaxQuant conditions were the following: Peptide FDR, 0.01; Protein FDR, 0.01; Min. peptide Length, 5; Variable modifications, Oxidation (M); Acetyl (Protein N-term); Acetyl (K); Dimethyl (KR); Fixed modifications, Carbamidomethyl (C); Peptides for protein quantitation, razor and unique; Min. peptides, 2; Min. ratio count, 2. Proteins were validated on the basis of at least 1 unique peptide detected.

\subsection{Cell Sorting with Flow Cytometry}

Mice were euthanized at the age of 2 or $7-8$ months by $\mathrm{CO}_{2}$ asphyxiation following cervical dislocation or cardiac puncture. Testes were removed, minced and digested with $50 \mu \mathrm{g} / \mathrm{mL}$ DNase 1 and $1 \mathrm{mg} / \mathrm{mL}$ Collagenase D in Hanks' solution at $37^{\circ} \mathrm{C}$ for $45 \mathrm{~min}$. The isolated cells were washed and suspended in PBS, and the cell suspension was filtered through a silk cloth (pore size $77 \mu \mathrm{m}$ ). Cells were incubated with unconjugated CD16/32 antibody (clone 2.4G2; Bio X Cell, Lebanon, NH, USA) to block the unspecific binding to low-affinity Fc-receptors and then stained for $30 \mathrm{~min}$ at $4{ }^{\circ} \mathrm{C}$ with the following antibodies: Anti-CD45-PerCP-Cy5,5 (clone 3O-F11; BD, Franklin Lakes, NJ, USA), anti-F4/80-A488 (clone BM8; eBioscience, San Diego, CA, USA), anti-CD11b-BV786 (clone M1/70; BD, Franklin Lakes, NJ, USA), anti-CD206-BV650 (clone C068C2; BioLegend, San Diego, CA, USA), anti-MHC II-PE (clone M5/114.15.2; BD, Franklin Lakes, NJ, USA), anti-CD11cBV711 (clone HL3; BD, Franklin Lakes, NJ, USA), anti-Ly6C-BV421 (clone AL-21; BD, 
Franklin Lakes, NJ, USA), anti-TRPV2 (HPA044993; Sigma-Aldrich, St. Louis, MO, USA) conjugated with a secondary $\alpha-\mathrm{Rb}$ A647 (A27040, Invitrogen, Carlsbad, CA, USA), diluted to the FACS-buffer. Cells were washed and fixed with $1 \%$ formaldehyde in PBS. Samples were acquired with the LSRFortessa flow cytometer (BD, Franklin Lakes, NJ, USA), and data were analyzed with the FlowJo software (FlowJo LLC, Ashland, OR, USA).

For subsequent quantitative RT-PCR analysis, wild-type $\mathrm{CD} 45^{+} \mathrm{CD} 11 \mathrm{~b}^{+} \mathrm{F} 4 / 80^{+}$cells were sorted for either CD206 ${ }^{+} \mathrm{MHC} \mathrm{II}^{-}$or CD206-MHC $\mathrm{II}^{+}$using a Sony SH800 cell sorter (100 $\mu \mathrm{m}$ nozzle, Sony Biotechnology Inc., San Jose, CA, USA). The purity of the isolated populations was $>95 \%$. The gating strategies for flow cytometric analyses are shown in Figure S4.

\subsection{Organotypic Testicular Tissue Incubation}

Freshly isolated testes from young WT animals ( $2-3$ months, $n=7)$ were decapsulated, divided into four equally sized tissue pieces, placed into individual wells of a 24-well plate containing DMEM/F12 (Gibco, Paisley, UK) and incubated with CB1 (AM251, 80 nM; Tocris Bioscience, Bristol, UK) and CB2 blockers (AM630, $800 \mathrm{nM}$; Tocris Bioscience, Bristol, UK), respectively, for $1 \mathrm{~h}$ at $37{ }^{\circ} \mathrm{C}, 5 \% \mathrm{CO}_{2}$, and $95 \%$ humidity on a rocking platform. After this pre-incubation, $\mathrm{CBD}$ (Tocris Bioscience, Bristol, UK) was added at a final concentration of $30 \mu \mathrm{M}$, with EtOH in equal volume as the solvent control and the tissue pieces were incubated for another $6 \mathrm{~h}$. Afterwards, tissue pieces were frozen in liquid nitrogen, stored at $-80{ }^{\circ} \mathrm{C}$ for RNA isolation. Supernatants were collected, frozen, and stored for further analysis in a proteome profiler.

\subsection{Proteome Profiler}

For this Proteome Profiler Mouse Cytokine Array Panel A (R\&D Systems, Minneapolis, MN, USA) supernatants of incubated testicular tissues treated with $30 \mu \mathrm{M}$ CBD or the EtOH solvent control of one 2.5 month-old wild-type animal were used following the manufacturer's instructions. Briefly, membranes were blocked and incubated with a mixture consisting of supernatant and corresponding buffer overnight. On the next day, the membrane was incubated with Detection Antibody Cocktail followed by streptavidinhorseradish-peroxidase for $1 \mathrm{~h}$ each. Finally, a Chemi Reagent Mix was added to measure chemiluminescence with an exposure time of $5 \mathrm{~min}$. The average spot signal density was measured, background subtracted, and normalized to the mRNA amount.

\subsection{Data Analysis and Statistics}

The testicular section of the above-listed animals subjected either to TRPV2 in situ hybridization or immunohistochemistry against F4/80 and TRPV2 were visualized using a Zeiss Axioplan microscope equipped with a Plan-Neofluar 40x/0.75 objective (Carl Zeiss Microscopy, Jena, Germany) and a Jenoptik camera (PROGRES GRYPHAX Arktur; Jenoptik, Jena, Germany) with the corresponding software (PROGRES GRYPHAX ${ }^{\circledR}$, Version 1.1.8.159 for Macintosh, 2017, Jenoptik Optical Systems GmbH, Jena, Germany). Microscopic images were further white-balanced and brightness was adjusted using Fiji (open source image processing package for ImageJ).

Quantitative RT-PCR datasets were analyzed using Microsoft Excel (2018, Microsoft, Redmond, WA, USA) and the statistical analysis was performed on the $\triangle \mathrm{Cq}$ values of each animal/treated tissue using Prism 7 (GraphPad, San Diego, CA, USA). After outlier exclusion (ROUT method, $Q=1 \%$ ), datasets were checked for Gaussian distribution using the Shapiro-Wilk normality test $(\alpha=0.05)$ and were subjected either to an unpaired (animals with different age, genotype and treatment, unpaired conditions) or paired (organotypic testicular tissue incubation, paired conditions) two-tailed t-tests. Datasets of wild-type macrophages sorted for their CD206 and MHC II expression and further subjected to quantitative RT-PCR looking for TRPV2 (Figure 1F) were not statistically investigated due to the low $n$ in this approach ( 2 months, $n=1$, pool of three animals; $7-8$ months, $n=2$, pool of three animals each). 
For analysis of mass spectrometry datasets, the measured iBAQ intensities were checked for Gaussian distribution using the Shapiro-Wilk normality test $(\alpha=0.05)$ followed by an unpaired two-tailed $t$-test, for those proteins detected in all three biological replicates of each group (3/3). The differential protein expression between the two genotypes is expressed as fold change based on the mean WT $\log 2$ iBAQ intensity.

For analysis of the FACS datasets, calculated percentages of the corresponding macrophage subpopulations were checked for Gaussian distribution using the Shapiro-Wilk normality test $(\alpha=0.05)$, and were further subjected to an unpaired two-tailed $t$-test when all three biological replicates of each group (3/3) showed values greater than 0 .

For all the tests, $\alpha$ was set to $0.05\left({ }^{*} p \leq 0.05,{ }^{* *} p \leq 0.01,{ }^{* * *} p \leq 0.001\right)$, and data are depicted as mean \pm SEM.

Signal densities of Western Blot bands and Proteome Profiler spots were measured using Fiji and further quantifications were done with Excel and Prism 7. Due to the low $n$ in both approaches (Western Blots: $n=2$ for each group; proteome profiler: $n=1$ ), no statistical analysis was performed.

Supplementary Materials: The following are available online at https:/ /www.mdpi.com/article/10 .3390/ijms22094727/s1.

Author Contributions: K.E. and A.M. (Artur Mayerhofer) conceived of and designed the experiments; K.E. performed the majority of the experiments, corresponding analysis, and interpretation; P.R. performed the FACS experiments and analysis; K.E., H.G., A.M. (Annika Missel), N.S., and L.W. generated testicular samples; C.H. supported the in situ hybridization experiments; S.L. performed the MS experiments and analysis; S.L., A.I., P.R., L.S., M.P., and A.M. (Artur Mayerhofer) contributed reagents/materials/analysis tools; K.E. and A.M. (Artur Mayerhofer) drafted the paper and all authors contributed to the final version. All authors have read and agreed to the published version of the manuscript.

Funding: This study was supported partly in parts by grants from Deutsche Forschungsgemeinschaft (DFG), especially MA1080/27-1 and 31-1 (project number 456828204) and SFB1123 TP Z02, and by grants from Deutscher Akademischer Austauschdienst (DAAD) and the Academy of Finland.

Institutional Review Board Statement: The animals were handled in accordance with the institutional animal care policies of the University of Turku (Turku, Finland). The number for animal license is KEK/2018-0608-Strauss.

Informed Consent Statement: Not applicable.

Data Availability Statement: Not applicable.

Acknowledgments: We thank Etta-Liisa Väänänen, Laura Grönfors, Emmi Lokka, and Hanna Heikelä for expert technical help and the Cell Imaging and Cytometry Core facility (Turku Bioscience, University of Turku, Åbo Akademi University, and Biocenter Finland) is acknowledged for services, instrumentation, and expertise. We are very grateful to Astrid Tiefenbacher and Nicole Kreitmair, as well as Melanie Kaseder and Verena Kast for the excellent laboratory support. The authors also thank Ignasi Forne of the Protein Analysis Unit (ZfP) of BioMedical Center, LMU, for assistance in the MS measurements.

Conflicts of Interest: The authors declare no conflict of interest. The funding sponsors had no role in the design of the study, in the collection, analysis, or interpretation of data, in the writing of the manuscript, and in the decision to publish the results. This work was done in partial fulfillment of the requirements of a doctoral thesis of K.E. at LMU, Munich.

\section{References}

1. Li, X.; Nokkala, E.; Yan, W.; Streng, T.; Saarinen, N.; Wärri, A.; Huhtaniemi, I.; Santti, R.; Mäkelä, S.; Poutanen, M. Altered structure and function of reproductive organs in transgenic male mice overexpressing human aromatase. Endocrinology 2001, 142, 2435-2442. [CrossRef] [PubMed]

2. Li, X.; Mäkelä, S.; Streng, T.; Santti, R.; Poutanen, M. Phenotype characteristics of transgenic male mice expressing human aromatase under ubiquitin C promoter. J. Steroid Biochem. Mol. Biol. 2003, 86, 469-476. [CrossRef]

3. Lahiri, S.; Walenta, L.; Aftab, W.; Strauss, L.; Poutanen, M.; Mayerhofer, A.; Imhof, A. Imaging mass spectrometry and shotgun proteomics reveal dysregulated pathways in hormone induced male infertility. bioRxiv 2020. [CrossRef] 
4. $\quad$ Aguilar-Pimentel, J.A.; Cho, Y.L.; Gerlini, R.; Calzada-Wack, J.; Wimmer, M.; Mayer-Kuckuk, P.; Adler, T.; Schmidt-Weber, C.B.; Busch, D.H.; Fuchs, H.; et al. Increased estrogen to androgen ratio enhances immunoglobulin levels and impairs B cell function in male mice. Sci. Rep. 2020, 10, 18334. [CrossRef]

5. Ellem, S.J.; Wang, H.; Poutanen, M.; Risbridger, G.P. Increased endogenous estrogen synthesis leads to the sequential induction of prostatic inflammation (prostatitis) and prostatic pre-malignancy. Am. J. Pathol. 2009, 175, 1187-1199. [CrossRef] [PubMed]

6. Li, X.; Strauss, L.; Mäkelä, S.; Streng, T.; Huhtaniemi, I.; Santti, R.; Poutanen, M. Multiple structural and functional abnormalities in the p450 aromatase expressing transgenic male mice are ameliorated by a p450 aromatase inhibitor. Am. J. Pathol. 2004, 164, 1039-1048. [CrossRef]

7. Li, X.; Strauss, L.; Kaatrasalo, A.; Mayerhofer, A.; Huhtaniemi, I.; Santti, R.; Mäkelä, S.; Poutanen, M. Transgenic mice expressing p450 aromatase as a model for male infertility associated with chronic inflammation in the testis. Endocrinology 2006, 147, 1271-1277. [CrossRef]

8. Frungieri, M.B.; Calandra, R.S.; Lustig, L.; Meineke, V.; Köhn, F.M.; Vogt, H.J.; Mayerhofer, A. Number, distribution pattern, and identification of macrophages in the testes of infertile men. Fertil. Steril. 2002, 78, 298-306. [CrossRef]

9. Adam, M.; Urbanski, H.F.; Garyfallou, V.T.; Welsch, U.; Köhn, F.M.; Ullrich Schwarzer, J.; Strauss, L.; Poutanen, M.; Mayerhofer, A. High levels of the extracellular matrix proteoglycan decorin are associated with inhibition of testicular function. Int. J. Androl. 2012, 35, 550-561. [CrossRef] [PubMed]

10. DeFalco, T.; Bhattacharya, I.; Williams, A.V.; Sams, D.M.; Capel, B. Yolk-sac-derived macrophages regulate fetal testis vascularization and morphogenesis. Proc. Natl. Acad. Sci. USA 2014, 111, E2384-E2393. [CrossRef]

11. Gaytan, F.; Bellido, C.; Aguilar, E.; van Rooijen, N. Requirement for testicular macrophages in Leydig cell proliferation and differentiation during prepubertal development in rats. J. Reprod. Fertil. 1994, 102, 393-399. [CrossRef] [PubMed]

12. DeFalco, T.; Potter, S.J.; Williams, A.V.; Waller, B.; Kan, M.J.; Capel, B. Macrophages Contribute to the Spermatogonial Niche in the Adult Testis. Cell Rep. 2015, 12, 1107-1119. [CrossRef]

13. Fijak, M.; Meinhardt, A. The testis in immune privilege. Immunol. Rev. 2006, 213, 66-81. [CrossRef] [PubMed]

14. Wang, L.L.; Li, Z.H.; Hu, X.H.; Muyayalo, K.P.; Zhang, Y.H.; Liao, A.H. The roles of the PD-1/PD-L1 pathway at immunologically privileged sites. Am. J. Reprod. Immunol. 2017, 78, e12710. [CrossRef] [PubMed]

15. Wang, M.; Fijak, M.; Hossain, H.; Markmann, M.; Nüsing, R.M.; Lochnit, G.; Hartmann, M.F.; Wudy, S.A.; Zhang, L.; Gu, H.; et al. Characterization of the Micro-Environment of the Testis that Shapes the Phenotype and Function of Testicular Macrophages. J. Immunol. 2017, 198, 4327-4340. [CrossRef]

16. Meinhardt, A.; Wang, M.; Schulz, C.; Bhushan, S. Microenvironmental signals govern the cellular identity of testicular macrophages. J. Leukoc. Biol. 2018, 104, 757-766. [CrossRef]

17. Matzkin, M.E.; Valchi, P.; Riviere, E.; Rossi, S.P.; Tavalieri, Y.E.; Muñoz de Toro, M.M.; Mayerhofer, A.; Bartke, A.; Calandra, R.S.; Frungieri, M.B. Aging in the Syrian hamster testis: Inflammatory-oxidative status and the impact of photoperiod. Exp. Gerontol. 2019, 124, 110649. [CrossRef]

18. Lokka, E.; Lintukorpi, L.; Cisneros-Montalvo, S.; Mäkelä, J.A.; Tyystjärvi, S.; Ojasalo, V.; Gerke, H.; Toppari, J.; Rantakari, P.; Salmi, M. Generation, localization and functions of macrophages during the development of testis. Nat. Commun. 2020, 11, 4375. [CrossRef]

19. Wang, M.; Yang, Y.; Cansever, D.; Wang, Y.; Kantores, C.; Messiaen, S.; Moison, D.; Livera, G.; Chakarov, S.; Weinberger, T.; et al. Two populations of self-maintaining monocyte-independent macrophages exist in adult epididymis and testis. Proc. Natl. Acad. Sci. USA 2021, 118, e2013686117. [CrossRef]

20. Perálvarez-Marín, A.; Doñate-Macian, P.; Gaudet, R. What do we know about the transient receptor potential vanilloid 2 (TRPV2) ion channel? FEBS J. 2013, 280, 5471-5487. [CrossRef]

21. Caterina, M.J.; Rosen, T.A.; Tominaga, M.; Brake, A.J.; Julius, D. A capsaicin-receptor homologue with a high threshold for noxious heat. Nature 1999, 398, 436-441. [CrossRef]

22. Park, U.; Vastani, N.; Guan, Y.; Raja, S.N.; Koltzenburg, M.; Caterina, M.J. TRP vanilloid 2 knock-out mice are susceptible to perinatal lethality but display normal thermal and mechanical nociception. J. Neurosci. 2011, 31, 11425-11436. [CrossRef]

23. Neeper, M.P.; Liu, Y.; Hutchinson, T.L.; Wang, Y.; Flores, C.M.; Qin, N. Activation properties of heterologously expressed mammalian TRPV2: Evidence for species dependence. J. Biol. Chem. 2007, 282, 15894-15902. [CrossRef]

24. Hu, H.Z.; Gu, Q.; Wang, C.; Colton, C.K.; Tang, J.; Kinoshita-Kawada, M.; Lee, L.Y.; Wood, J.D.; Zhu, M.X. 2-aminoethoxydiphenyl borate is a common activator of TRPV1, TRPV2, and TRPV3. J. Biol. Chem. 2004, 279, 35741-35748. [CrossRef] [PubMed]

25. Qin, N.; Neeper, M.P.; Liu, Y.; Hutchinson, T.L.; Lubin, M.L.; Flores, C.M. TRPV2 is activated by cannabidiol and mediates CGRP release in cultured rat dorsal root ganglion neurons. J. Neurosci. 2008, 28, 6231-6238. [CrossRef] [PubMed]

26. Maggi, C.A.; Santicioli, P.; Geppetti, P.; Parlani, M.; Astolfi, M.; Pradelles, P.; Patacchini, R.; Meli, A. The antagonism induced by ruthenium red of the actions of capsaicin on the peripheral terminals of sensory neurons: Further studies. Eur. J. Pharmacol. 1988, 154, 1-10. [CrossRef]

27. Nie, L.; Oishi, Y.; Doi, I.; Shibata, H.; Kojima, I. Inhibition of proliferation of MCF-7 breast cancer cells by a blocker of Ca ${ }^{2+}{ }_{-}$ permeable channel. Cell Calcium 1997, 22, 75-82. [CrossRef]

28. Fricke, T.C.; Echtermeyer, F.; Zielke, J.; de la Roche, J.; Filipovic, M.R.; Claverol, S.; Herzog, C.; Tominaga, M.; Pumroy, R.A.; Moiseenkova-Bell, V.Y.; et al. Oxidation of methionine residues activates the high-threshold heat-sensitive ion channel TRPV2. Proc. Natl. Acad. Sci. USA 2019, 116, 24359-24365. [CrossRef] 
29. Shibasaki, K.; Murayama, N.; Ono, K.; Ishizaki, Y.; Tominaga, M. TRPV2 enhances axon outgrowth through its activation by membrane stretch in developing sensory and motor neurons. J. Neurosci. 2010, 30, 4601-4612. [CrossRef] [PubMed]

30. Hisanaga, E.; Nagasawa, M.; Ueki, K.; Kulkarni, R.N.; Mori, M.; Kojima, I. Regulation of calcium-permeable TRPV2 channel by insulin in pancreatic beta-cells. Diabetes 2009, 58, 174-184. [CrossRef]

31. Park, K.S.; Kim, Y.; Lee, Y.H.; Earm, Y.E.; Ho, W.K. Mechanosensitive cation channels in arterial smooth muscle cells are activated by diacylglycerol and inhibited by phospholipase C inhibitor. Circ. Res. 2003, 93, 557-564. [CrossRef]

32. Jang, Y.; Lee, Y.; Kim, S.M.; Yang, Y.D.; Jung, J.; Oh, U. Quantitative analysis of TRP channel genes in mouse organs. Arch. Pharm. Res. 2012, 35, 1823-1830. [CrossRef]

33. Stokes, A.J.; Shimoda, L.M.; Koblan-Huberson, M.; Adra, C.N.; Turner, H. A TRPV2-PKA signaling module for transduction of physical stimuli in mast cells. J. Exp. Med. 2004, 200, 137-147. [CrossRef] [PubMed]

34. Nagasawa, M.; Nakagawa, Y.; Tanaka, S.; Kojima, I. Chemotactic peptide fMetLeuPhe induces translocation of the TRPV2 channel in macrophages. J. Cell Physiol. 2007, 210, 692-702. [CrossRef] [PubMed]

35. Link, T.M.; Park, U.; Vonakis, B.M.; Raben, D.M.; Soloski, M.J.; Caterina, M.J. TRPV2 has a pivotal role in macrophage particle binding and phagocytosis. Nat. Immunol. 2010, 11, 232-239. [CrossRef]

36. Zhang, D.; Spielmann, A.; Wang, L.; Ding, G.; Huang, F.; Gu, Q.; Schwarz, W. Mast-cell degranulation induced by physical stimuli involves the activation of transient-receptor-potential channel TRPV2. Physiol. Res. 2012, 61, 113-124. [CrossRef] [PubMed]

37. Kajiya, H.; Okamoto, F.; Nemoto, T.; Kimachi, K.; Toh-Goto, K.; Nakayana, S.; Okabe, K. RANKL-induced TRPV2 expression regulates osteoclastogenesis via calcium oscillations. Cell Calcium 2010, 48, 260-269. [CrossRef] [PubMed]

38. Yamashiro, K.; Sasano, T.; Tojo, K.; Namekata, I.; Kurokawa, J.; Sawada, N.; Suganami, T.; Kamei, Y.; Tanaka, H.; Tajima, N.; et al. Role of transient receptor potential vanilloid 2 in LPS-induced cytokine production in macrophages. Biochem. Biophys. Res. Commun. 2010, 398, 284-289. [CrossRef] [PubMed]

39. Kanzaki, M.; Zhang, Y.Q.; Mashima, H.; Li, L.; Shibata, H.; Kojima, I. Translocation of a calcium-permeable cation channel induced by insulin-like growth factor-I. Nat. Cell Biol. 1999, 1, 165-170. [CrossRef]

40. Kowase, T.; Nakazato, Y.; Yoko, O.H.; Morikawa, A.; Kojima, I. Immunohistochemical localization of growth factor-regulated channel (GRC) in human tissues. Endocr. J. 2002, 49, 349-355. [CrossRef] [PubMed]

41. Lubahn, D.B.; Moyer, J.S.; Golding, T.S.; Couse, J.F.; Korach, K.S.; Smithies, O. Alteration of reproductive function but not prenatal sexual development after insertional disruption of the mouse estrogen receptor gene. Proc. Natl. Acad. Sci. USA 1993, 90, 11162-11166. [CrossRef]

42. Strauss, L.; Kallio, J.; Desai, N.; Pakarinen, P.; Miettinen, T.; Gylling, H.; Albrecht, M.; Mäkelä, S.; Mayerhofer, A.; Poutanen, M. Increased exposure to estrogens disturbs maturation, steroidogenesis, and cholesterol homeostasis via estrogen receptor alpha in adult mouse Leydig cells. Endocrinology 2009, 150, 2865-2872. [CrossRef]

43. Xu, Q.; Choksi, S.; Qu, J.; Jang, J.; Choe, M.; Banfi, B.; Engelhardt, J.F.; Liu, Z.G. NADPH Oxidases Are Essential for Macrophage Differentiation. J. Biol. Chem. 2016, 291, 20030-20041. [CrossRef] [PubMed]

44. Singel, K.L.; Segal, B.H. NOX2-dependent regulation of inflammation. Clin. Sci. 2016, 130, 479-490. [CrossRef] [PubMed]

45. Yu, W.; Zheng, H.; Lin, W.; Tajima, A.; Zhang, Y.; Zhang, X.; Zhang, H.; Wu, J.; Han, D.; Rahman, N.A.; et al. Estrogen promotes Leydig cell engulfment by macrophages in male infertility. J. Clin. Investig. 2014, 124, 2709-2721. [CrossRef]

46. Krege, J.H.; Hodgin, J.B.; Couse, J.F.; Enmark, E.; Warner, M.; Mahler, J.F.; Sar, M.; Korach, K.S.; Gustafsson, J.A.; Smithies, O. Generation and reproductive phenotypes of mice lacking estrogen receptor beta. Proc. Natl. Acad. Sci. USA 1998, 95, 15677-15682. [CrossRef] [PubMed]

47. Pfaffl, M.W. A new mathematical model for relative quantification in real-time RT-PCR. Nucleic Acids Res. 2001, 29, e45. [CrossRef] [PubMed] 